\title{
Research paper \\ National Culture Dimensions and World Bank Governance Indicators
}

\author{
Mohsen Dahmardeh Ghaleno' ${ }^{1}$, ${ }^{\text {,Hamid Zarei }}{ }^{2}$ (1)
}

1. MSc. in Accounting, Instructor, Department of Accounting, Faculty of Humanities, Higher Education Complex, Saravan, Iran. 2. MSc. in Accounting, Department of Accounting, Faculty of Management and Economics, University of Sistan and Baluchestan, Zahedan, Iran.

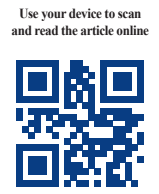

CFtation Dahmardeh Ghaleno, M., \& Zarei, H. (2018). National Culture Dimensions and World Bank Governance Indicators. Quarterly Journal of the Macro and Strategic Policies, 6(3), 346-375. http://dx.doi.org/10.32598/JMSP.6.3.346

\section{http://dx.doi.org/10.32598/JMSP.6.3.346}

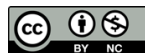

Funding: See Page 372

Received: 07 Mar 2018

Accepted: 15 Apr 2018

Available Online: 23 Sep 2018

Key words:

Hofstede National

Culture Dimensions,

World Bank Gov-

ernance Indicators,

Kaufmann dimensions

\section{A B STRACT}

Various theories of national culture around the world affect legal systems, social norms, economic development, and political communities. In this regard, this paper discusses the impact of national culture dimensions on worldwide governance indicators. The is an applied research with quasi-experimental design and regressive approach. The population of this international study comprised all nations worldwide, thus 74 countries were selected as study sample using non-random sampling method. The paper used six national culture dimensions of Hofstede et al. (2010) as explanatory variables. The institutions composite of six worldwide governance indicators from Kaufmann et al. (2010) in the World Bank were taken into account as the responsive variables of the paper. It is worth knowing that both studies are highly cited papers. Based on the results, power distance has a significant and negative relationship with institutions composite, but individualism, long-term orientation, and indulgence are significantly and positively related to the institutions composite. These findings are discussed subsequently.

JEL Classification: G30, G38, O17, O19, Z19.

* Corresponding Author:

Hamid Zarei, MSc.

Address: Department of Accounting, Faculty of Management and Economics, University of Sistan and Baluchestan, Zahedan, Iran.

Tel: +98 (917) 8574107

E-mail: hamidzarei@pgs.usb.ac.ir 


\section{ارزيابى ابعاد فرهنَّ ملى و شاخصهاى راهبردى بانك جهانى}

محسن دهمرده قلعه نو' (i) " *مميد زارعى

1 - كارشئاس ارشّد حسابدارى، مربى، كروه حسابدارى، دانشكده علوم انسانى، مجتمع آموزش عالى سراوان، سراوان، ايران.

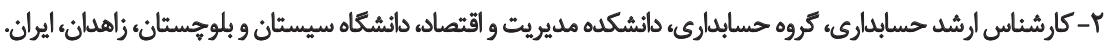

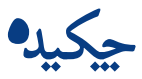

تاريخ دريافت:

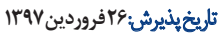

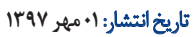

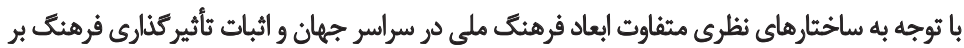

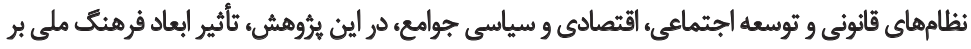

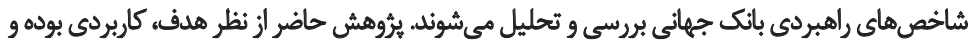

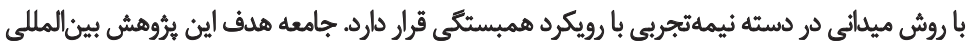

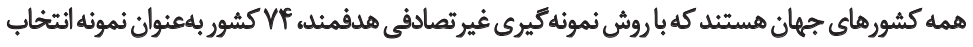

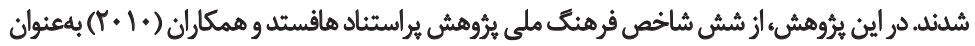

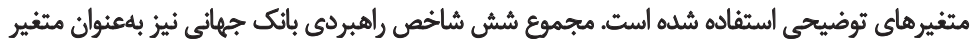

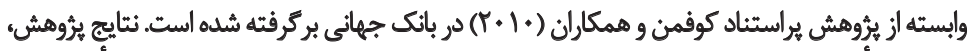

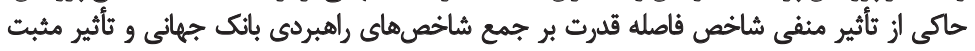

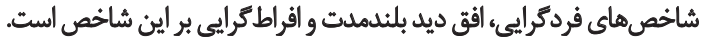

طبقهبندى G30, G38, O17, O19, Z19:JEL

\section{: Lofllg}

ابعاد فرهنى ملى مافيلى

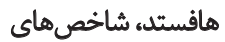
راهبردى بائك جهاني، شاخص كوفمن بائن
* نويسنده مسئول:

حميد زارعي - تويسن

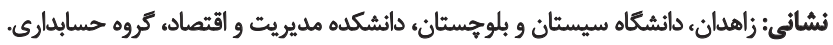

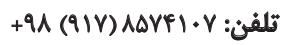

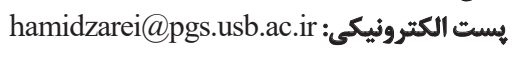




\section{dalo}

يثزوهش حاضر تبيين كننده نقش و تأثير شاخصهاى فرهنَ ملى 'بر شاخصهاى راهبردى بانك جهانى

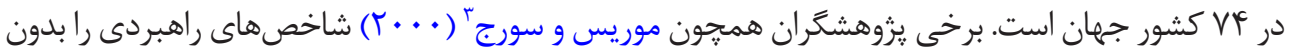

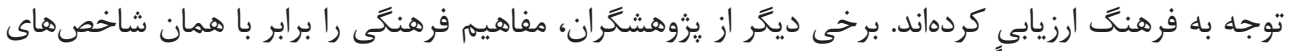

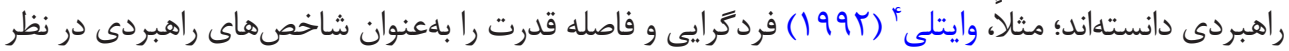

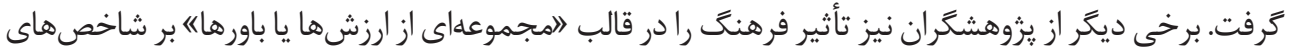

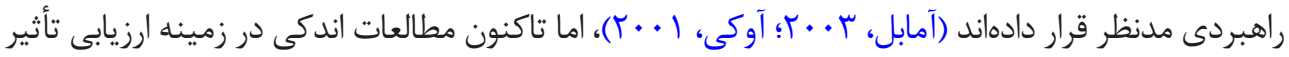

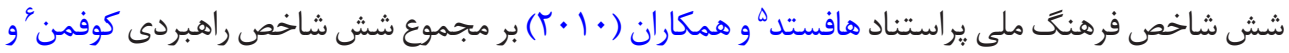

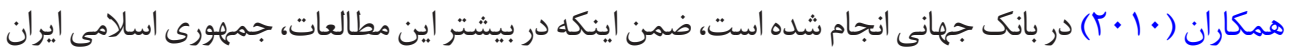

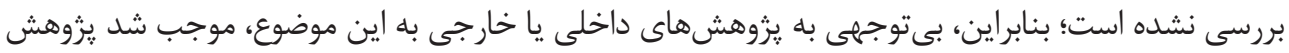

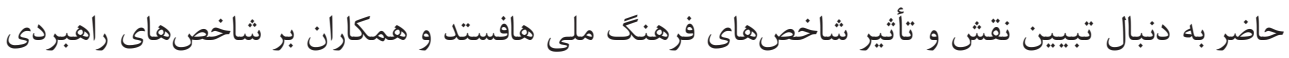

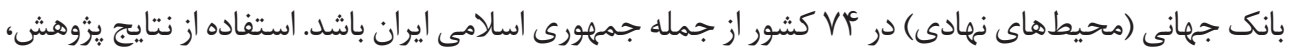

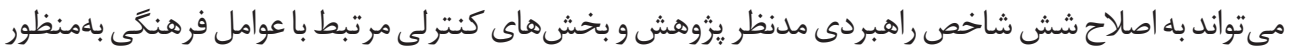
ييادهسازى و اجراى سياستهاى راهبردى مؤثر، كمك كند.

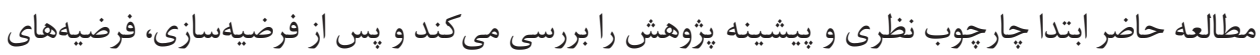

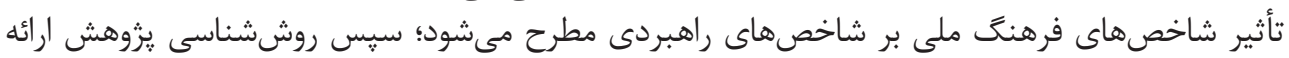

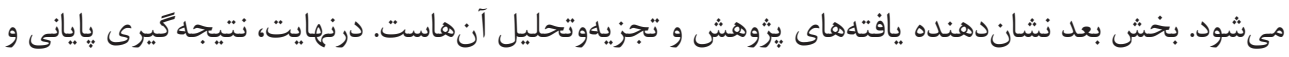

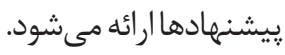

\section{1- ادبيات موضوع}

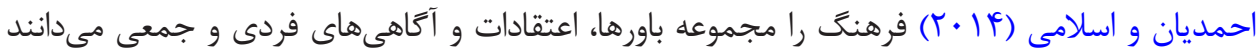

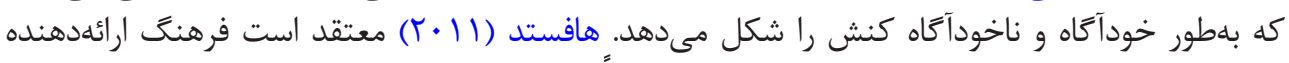

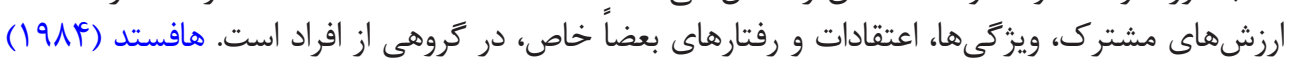

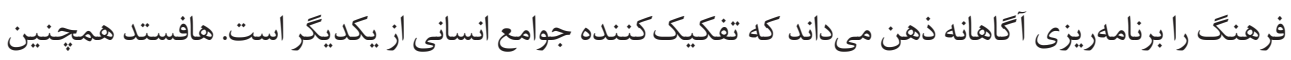

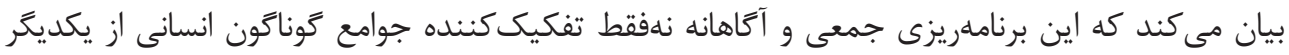

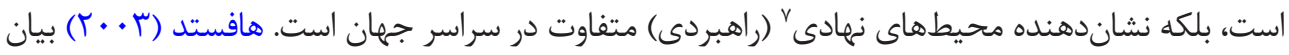

1. National culture dimensions

2. Worldwide Governance Indicators_WGI (Institutions)

3. Maurice and Sorge

4. Whitley

5. Hofstede

6. Kaufmann

7. Institutional Environments 
مى كند كه هنجارهاى اجتماعى و برنامهريزىهاى آَّاهانه مردم جامعه باعث تأثير فرهنَ بر محيطهاى نهادى

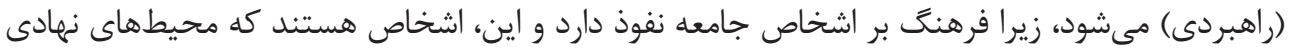

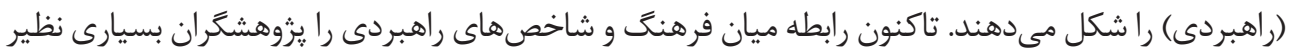

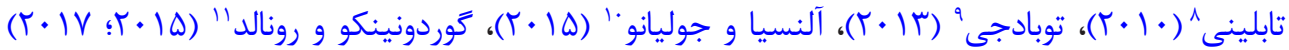

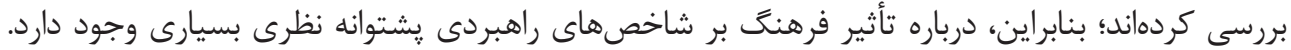

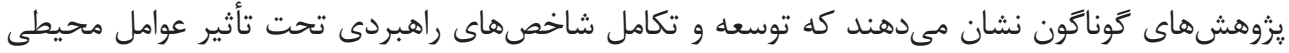

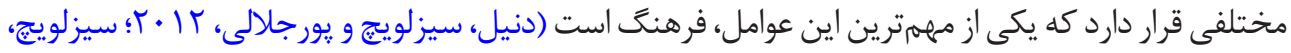

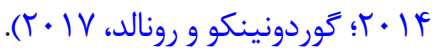

فرهنگَ، برنامهريزى فكرى جمعى در ذهن بشريت است كه اعضاى يك گروه را از ديخر زروهها متمايز

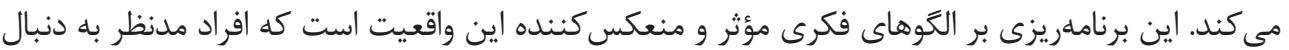

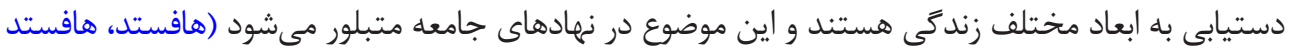

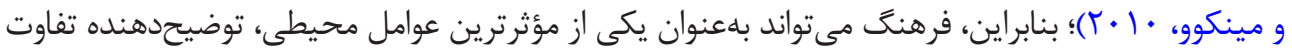

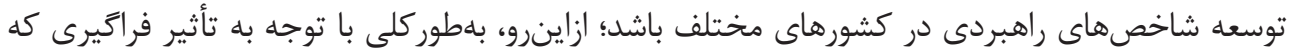

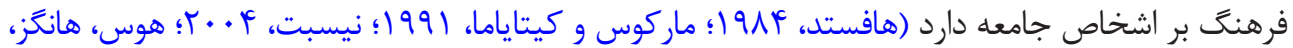

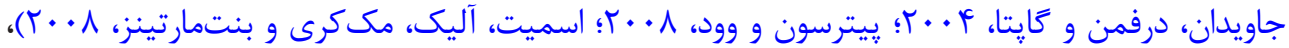

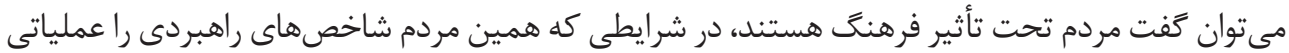

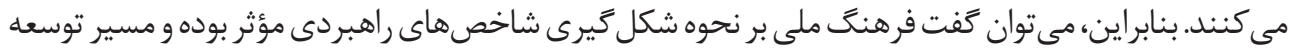

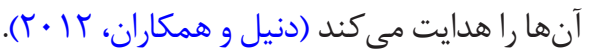

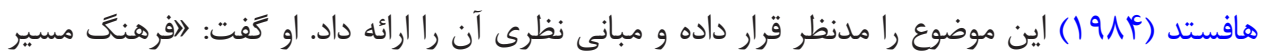

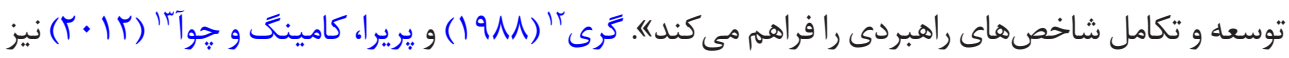

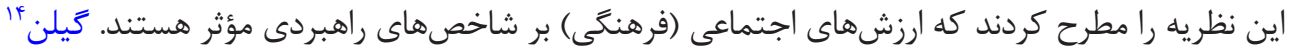

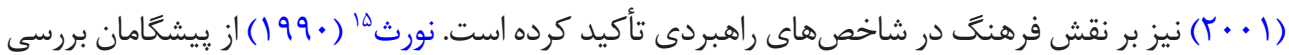

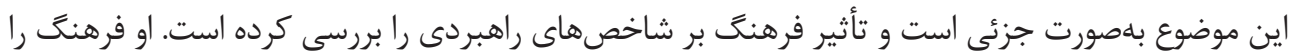

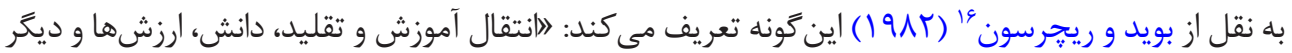

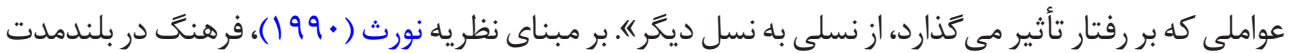

8. Tabellini

9. Tubadji

10. Alesina and Giuliano

11. Gorodnichenko and Roland

12. Gray

13. Perera, Cummings, \& Chua

14. Guillen

15. North

16. Boyd and Richerson 


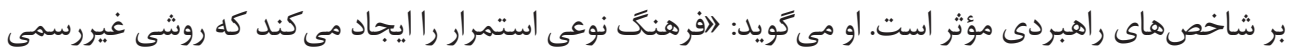

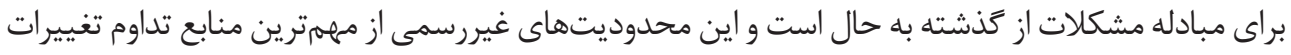
اجتماعى بهصورت بلندمدت هستند.

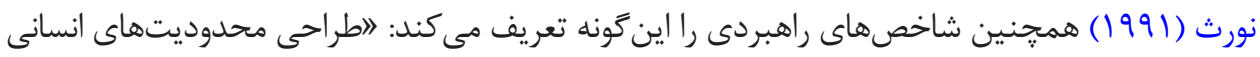

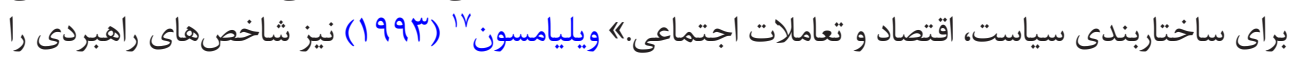

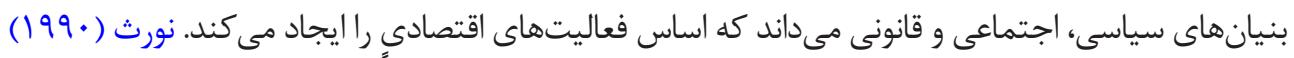

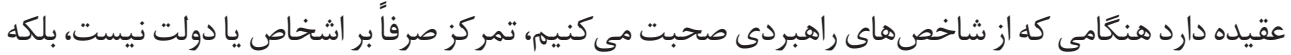

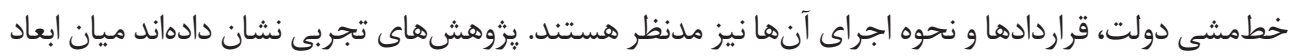

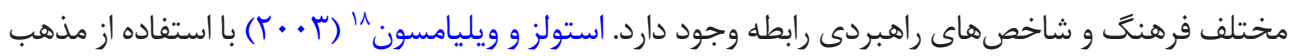

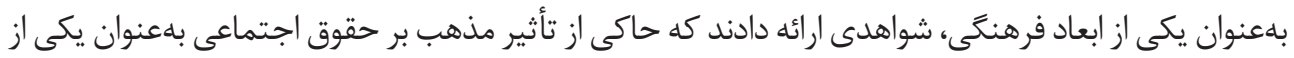

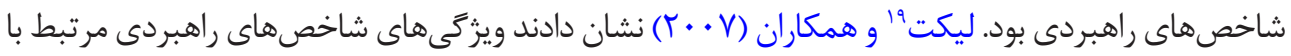

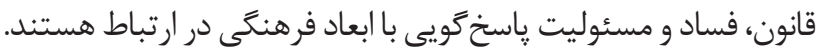

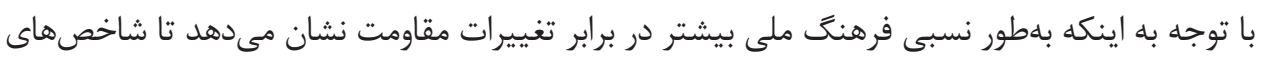

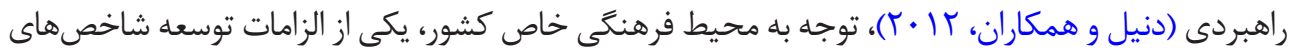

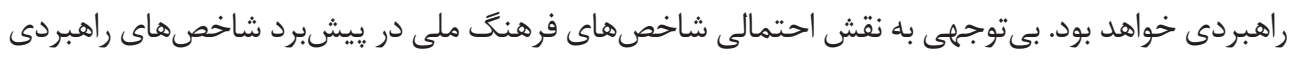

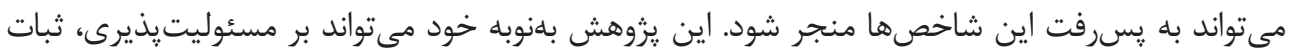

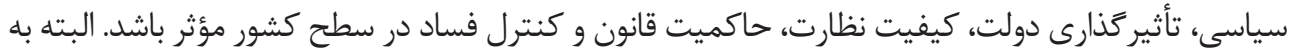

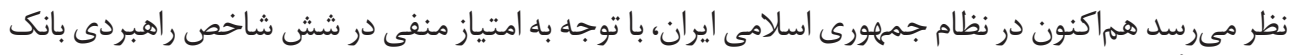

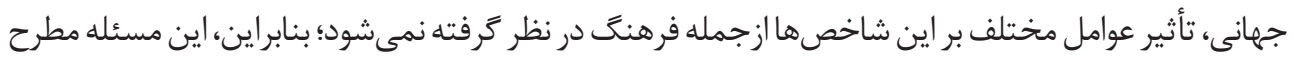

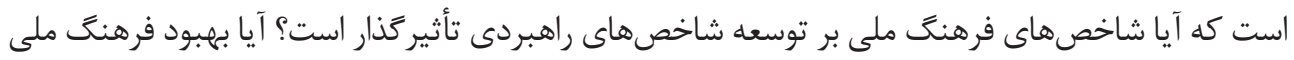

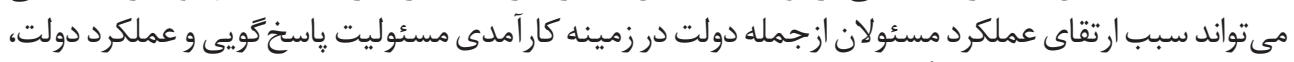

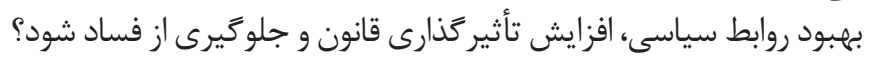

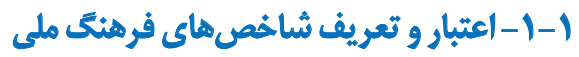

در اين يزوهش از شش شاخص فرهنَ ملى بهعنوان متغيرهاى توضيحى استفاده شده است. جهار شاخص

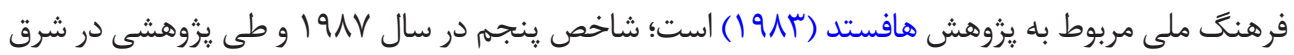

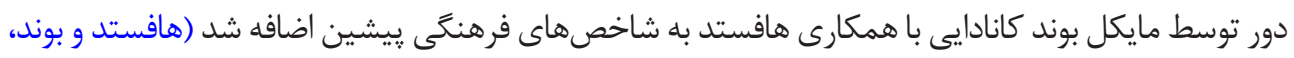

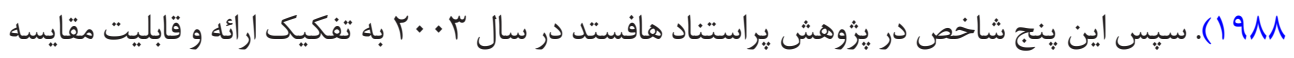

17. Williamson

18. Stulz and Williamson

19. Licht 


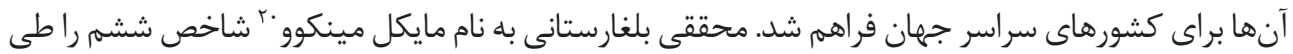

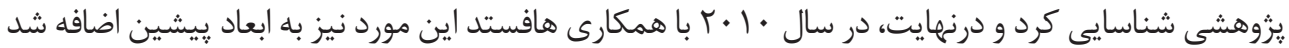

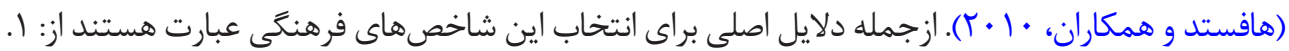

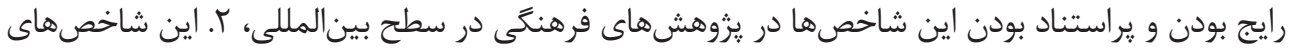

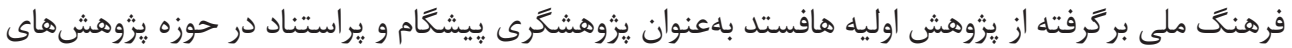

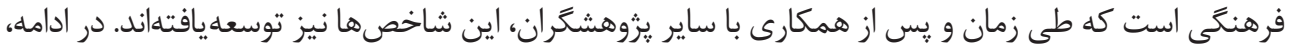

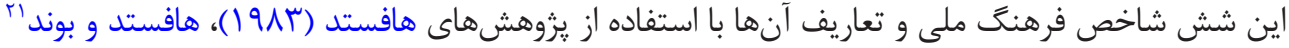

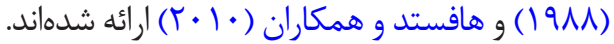

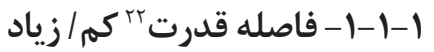

اين شاخص بيان مى كند كه اعضاى قدرتمند سازمان ها و مؤسسات انتظار دارند قدرت بهطور نامساوى توزيع

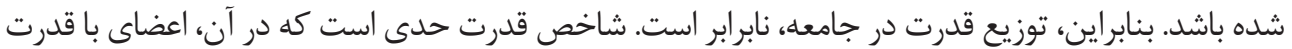

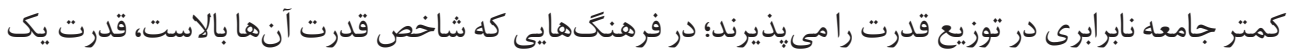

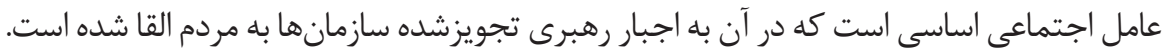

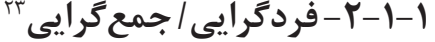

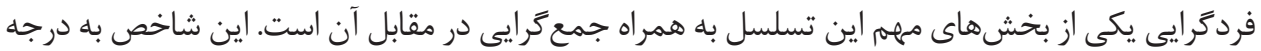

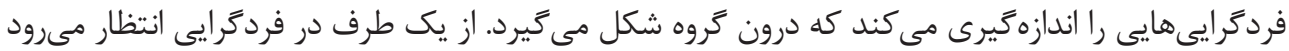

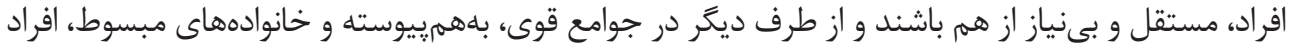

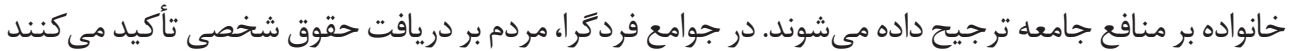

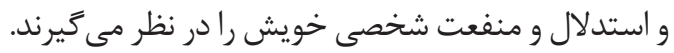

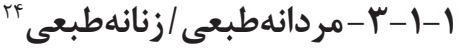

اين شاخص برحسب تسلسل با ويزگ مى هاى مردانهطبعى در يكطرف و خصوصيات زنانهطبعى در طرف ديكر

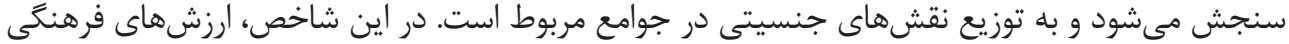

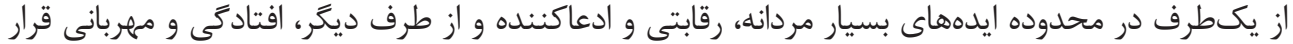

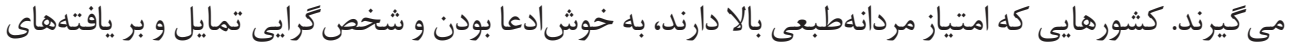

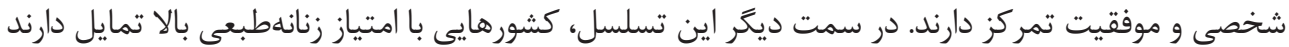

20. Michael Minkov

21. Bond

22. Power Distance

23. Individualism

24. Masculinity/ Femininity 
كه بر روابط تأكيد كنند، باضعيفترها مهربان هستند و كيفيت زندگى را به ثروت و تعلقات ترجيح مى دهند و

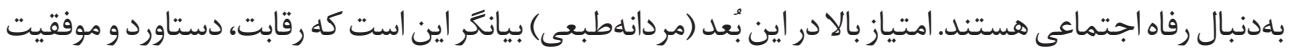

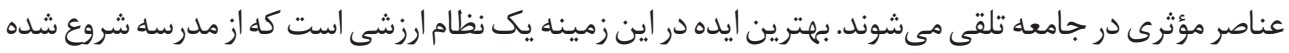

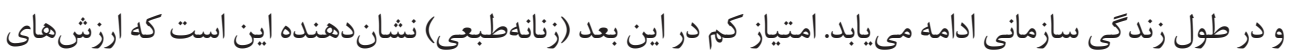

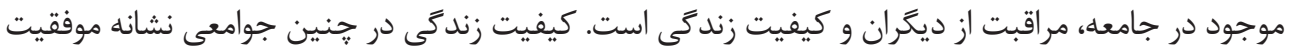

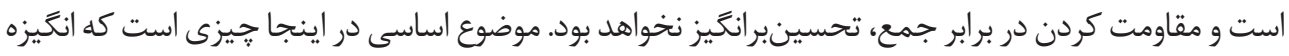

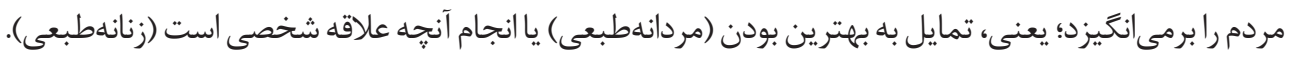

\section{|-1-1- ابهام كريزى كم/ زياد}

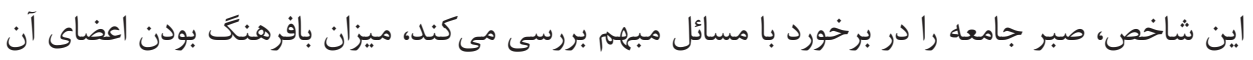

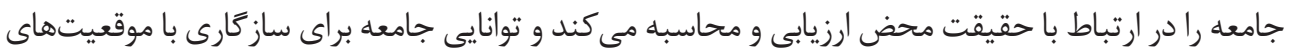

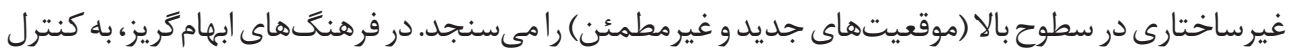

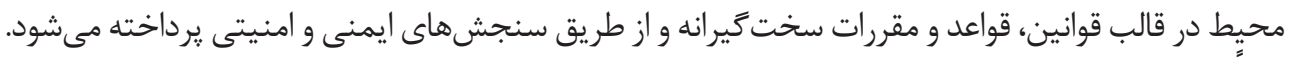

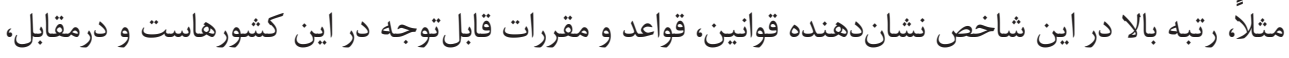

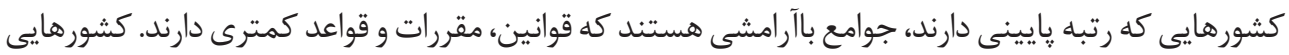

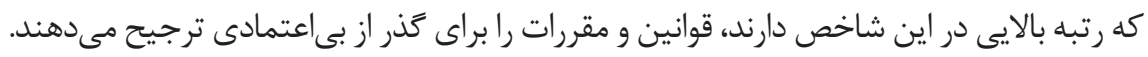

|-1- |- - - - افق ديد كو تاهمدت / بلندمدت

افق ديد كوتاهمدت نخرشى است كه بركذشته و حال تمركز دارد. در اين نخرش، سنتها جايخاه ويثراى دارند،

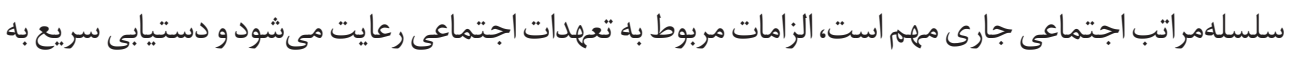

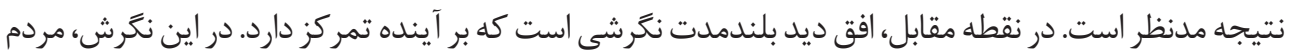

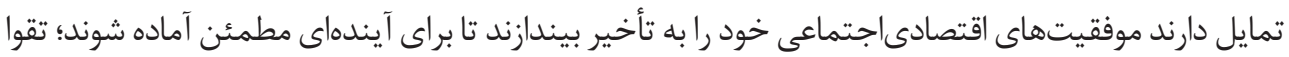

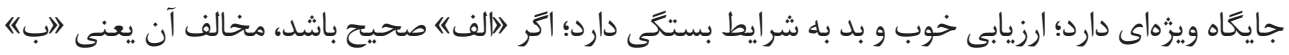

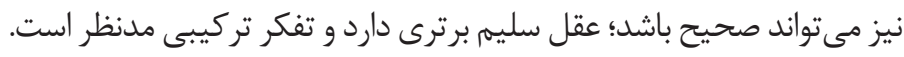

|-1-4- خويشتندارى /افراطگر ايیى

نَرش افراطگر ايى بر ميزان شاد بودن مردم جامعه، كنترل زندگَى، اوقات فراغت از كار و آزادى تمركز دارد.

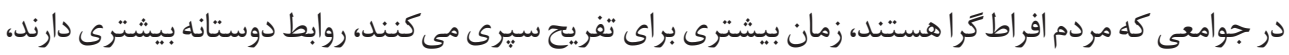

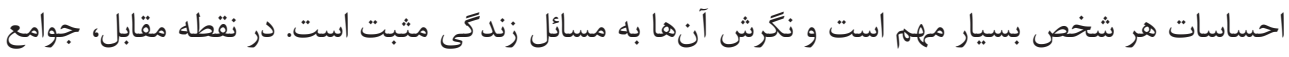

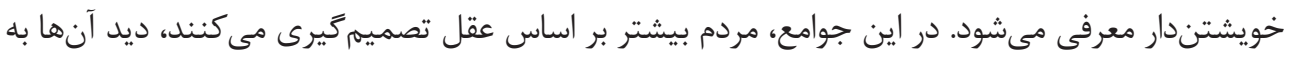

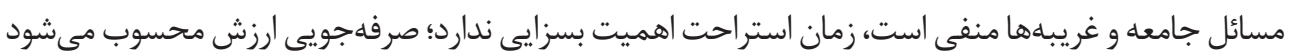
و يايبندى به اصول و عهد اهميت دارد. 


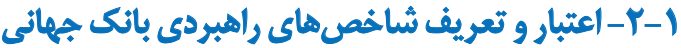

در اين يثوهش، مجموع شش شاخص راهبردى بانك جهانى در سطح ملى بهعنوان متغير وابسته براى

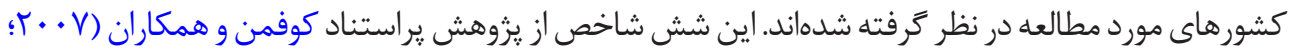

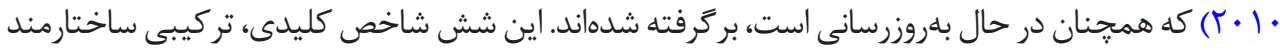

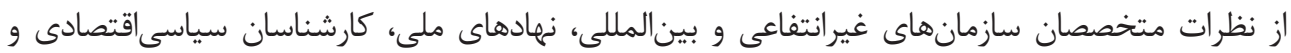

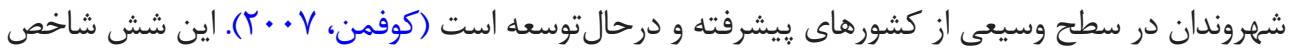

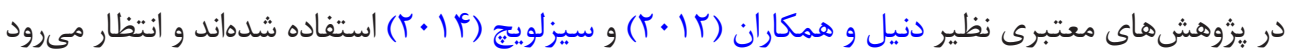

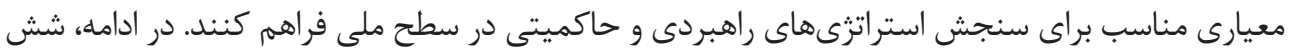

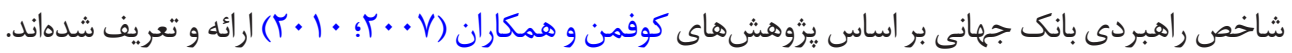

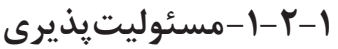

اين شاخص به ميزان مشاركت شهروندان در انتخاب دولت، آزادى بيان، آزادى اجتماعى و رسانه مربوط است.

$$
\text { ثبات سياسى - }
$$

اين شاخص بيان مى كند كه دولت در نتيجه اعمال خلاف قانون اساسى و اعمال خشونت بـرويه عليه

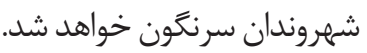

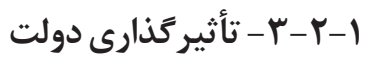

اين شاخص نشاندهنده كيفيت خدمات عمومى، كيفيت خدمات شهروندى، ميزان تأثيريذيرى دولت از

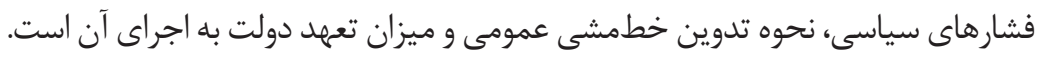

F- P- r-

اين شاخص مربوط به تدوين خطمشى صحيح و مقرراتى است كه موجب توسعه بخش خصوصى مىشود.

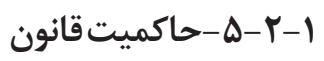

اين شاخص بيان كننده ميزان اعتماد به قوانين و وفادارى به آنها در سطح جامعه بهويزه كيفيت اجراى آنها توسط پِيس، دادكاهها و مراجع مرتبط است

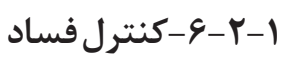

اين شاخص مربوط به ميزان نفوذ قدرت عمومى براى كسب منافع شخصى كم يا زياد در قالب فساد توسط مسئولان و نفعبرند مان در جامعه است مئن 


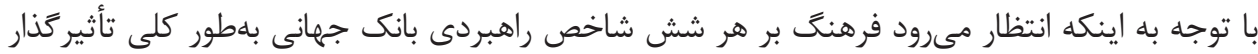

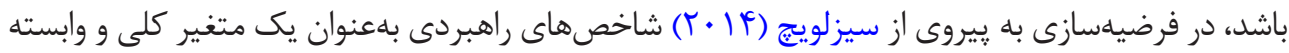

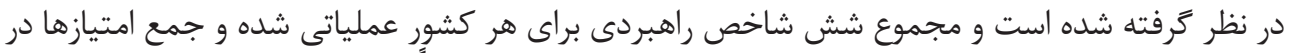

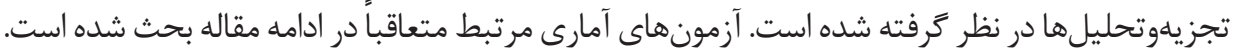

|r-r|r

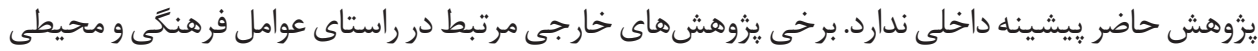

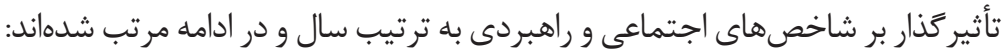

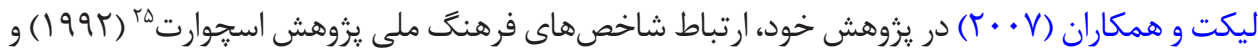

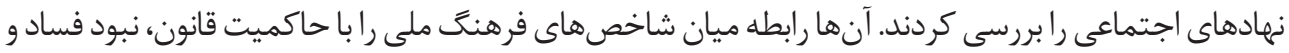

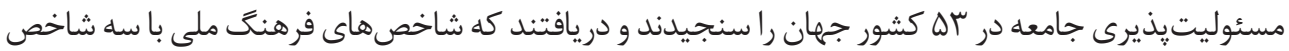

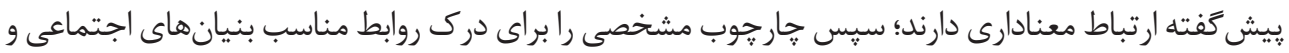
ارائه خطمشى براى انجام اصلاحات اقتصادى ارائه دادند

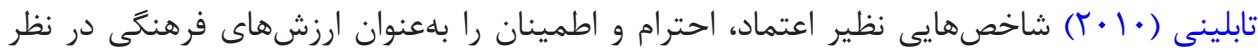

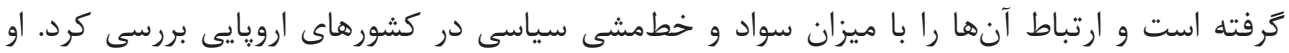

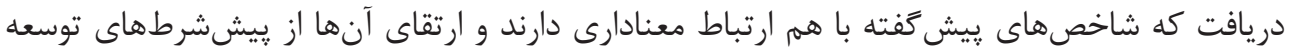
اقتصادىسياسى در كشورهاى ارويايى است.

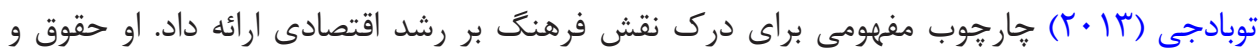

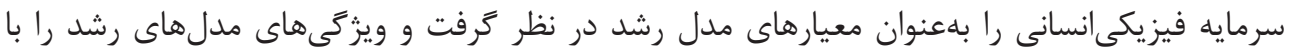

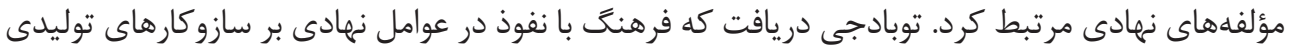

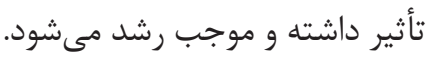

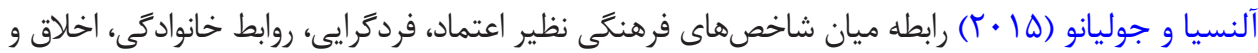

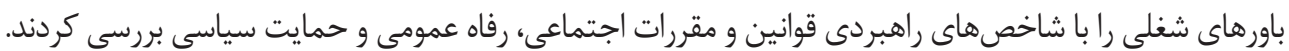

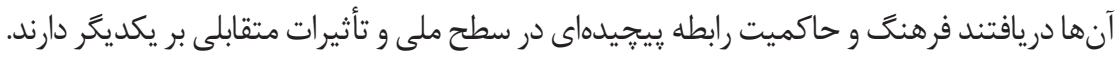

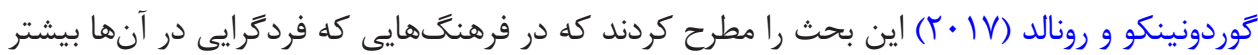

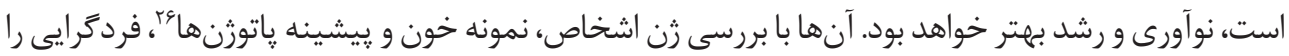

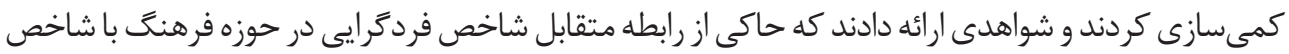

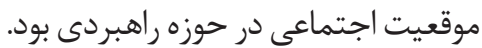




\section{|-ع - تأثير فر هنتَّى ملى بر شاخصهاى راهبردى}

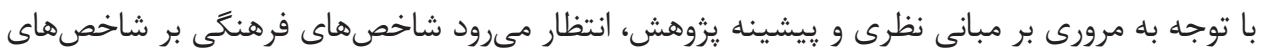

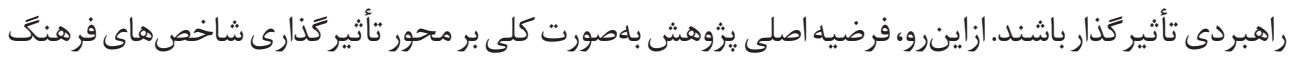

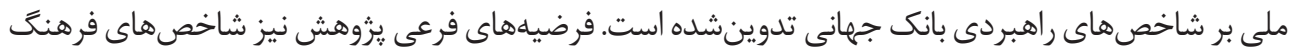

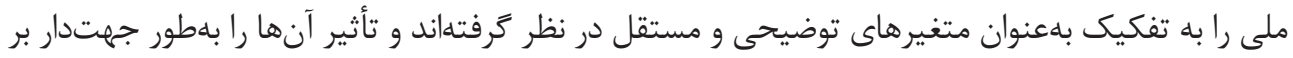

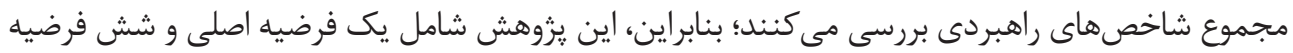

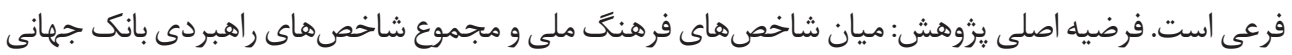
رابطه معنادارى وجود دارد.

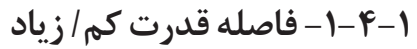

با توجه به تعريف فاصله قدرت و تبيين اينكه در يك جامعه با فاصله قدرت بالا، رهبران و مسئولان انتظار

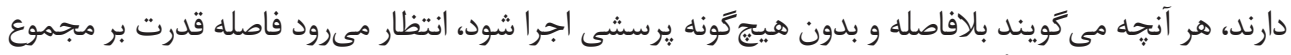

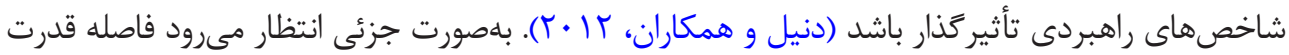

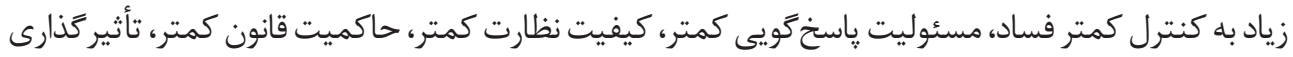

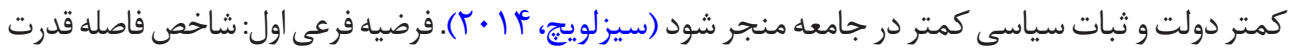
با مجموع شاخصهاى راهبردى بانك جهانى رابطه معنادار و منفى دارد.

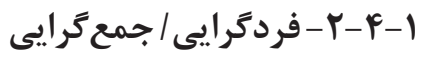

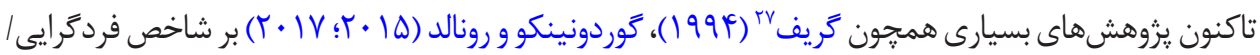

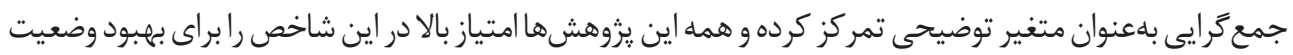

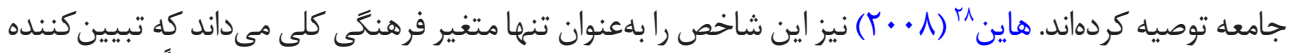

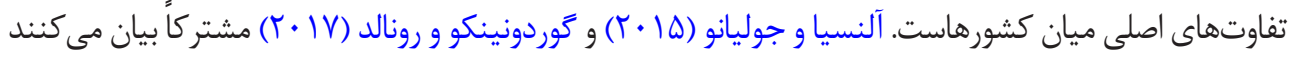

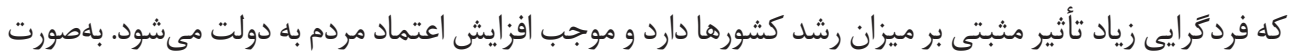

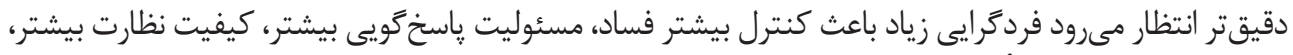

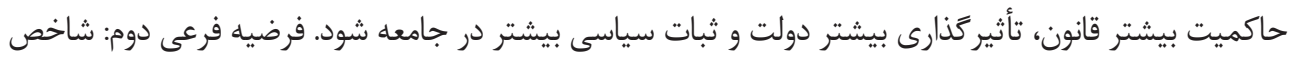

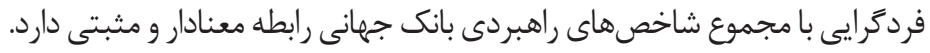

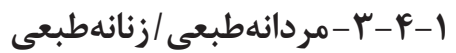

با توجه به تعريف مردانهطبعى/ زنانهطبعى و تبيين اينكه در كشورهايى كه مردانهطبعى زياد دارند، نتيجه 
نهايى مدنظر است (هافستد و همكاران، • (·؟). ازاينرو، مىتوان اين نظريه را مطرح كرد كه اولويت جنين

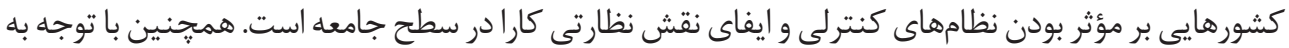

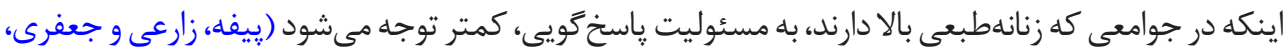

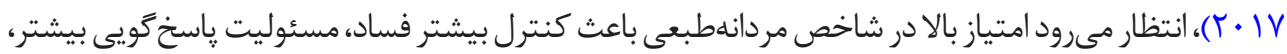

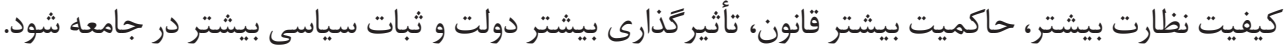

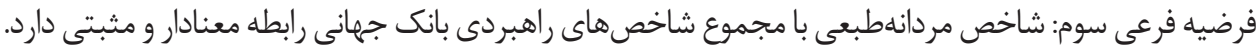

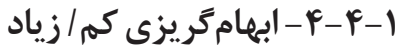

با توجه به تعريف ابهام گريزى و تبيين اينكه در فرهنگهاى ابهام گريز، جوامع به اعمال كنترل و نظارت بيشتر در قالب قوانين و مقررات مبادرت مىورزند، انتظار مىرود جوامعى كه امتياز بالايى در اين شاخص دارئ دارند، محيط

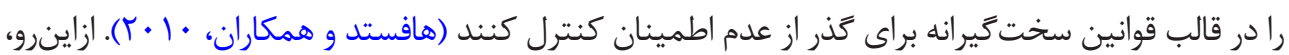

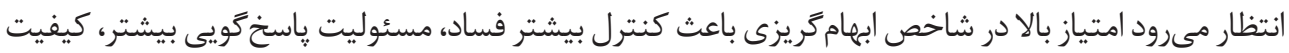

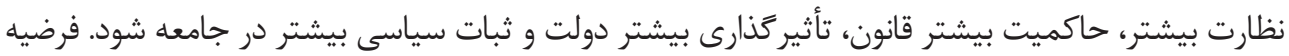

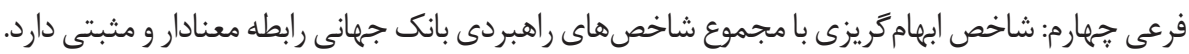

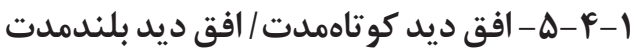

با توجه به ويزگَىهاى جوامعى كه افق ديد بلندمدت دارند، انتظار مىرود امتياز بالا در اين شاخص بر

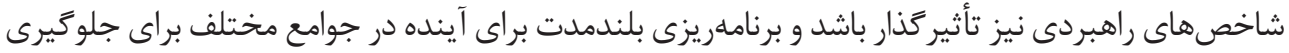

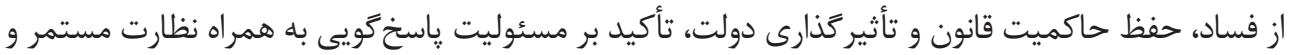

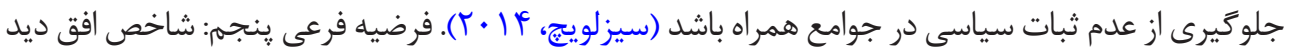

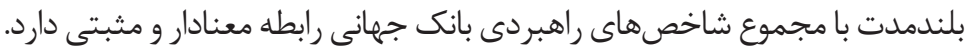

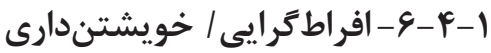

با توجه به تعريف اين شاخص، جوامعى كه افراطگرايى بالايى دارند، بيشتر به آزادى بيان، آزادى اجتماعى و

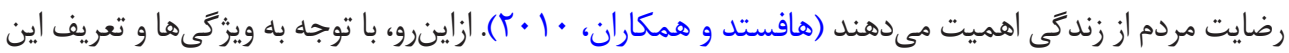

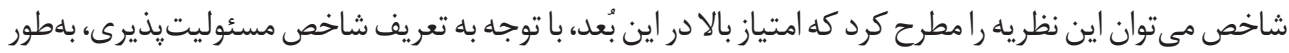

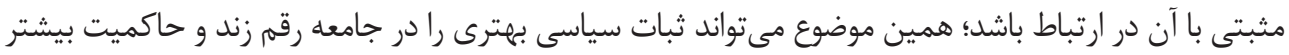

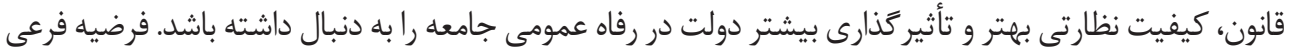

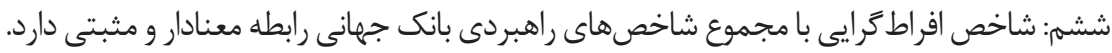




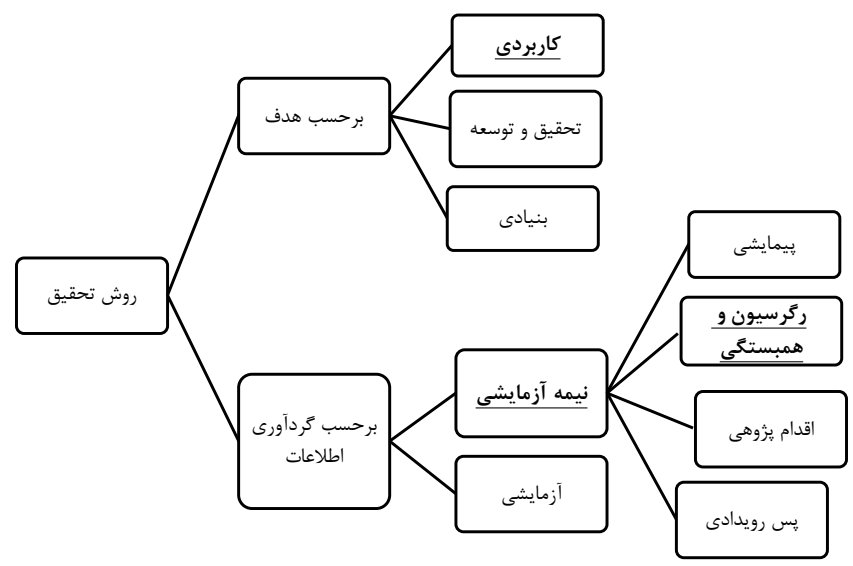

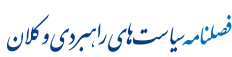

تصوير ا. انتخاب روش يُّوهش

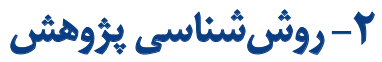

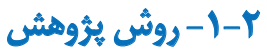

روشهاى : روهش بر اساس "هدف" و "روش گردآورى اطلاعاته در تصوير شماره ا دستلبندى شده

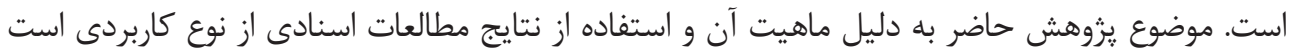

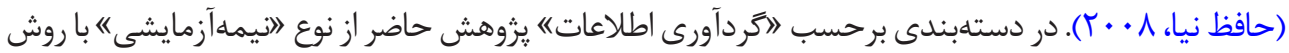

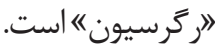

osls مناب

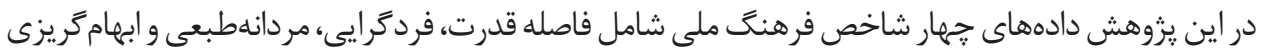

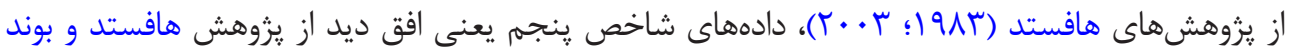

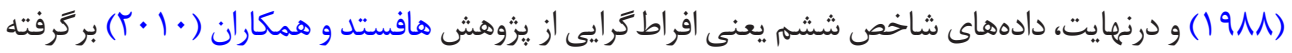

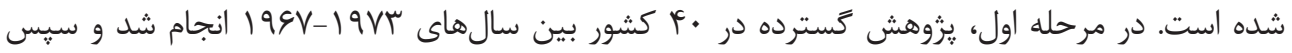

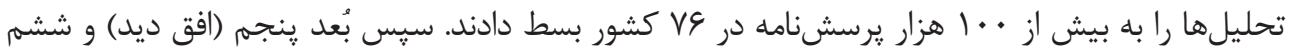

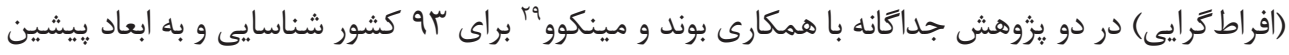

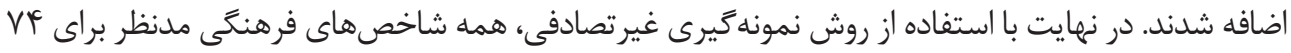

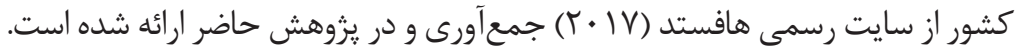

29. Minkov 
همجنين، شش شاخص راهبردى تحت يوشش بانك جهانى و در يزوهشى يراستناد كه همجنان در حال

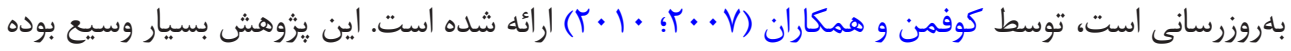

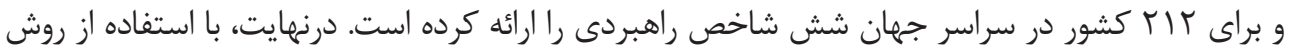

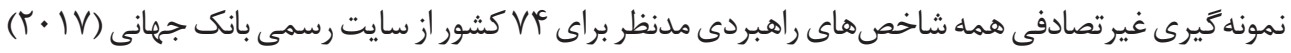

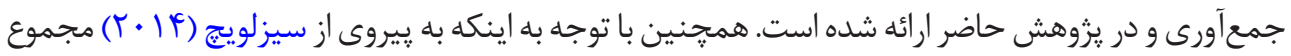

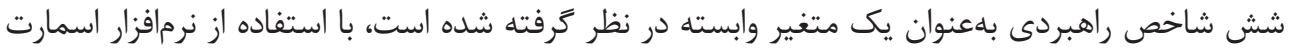

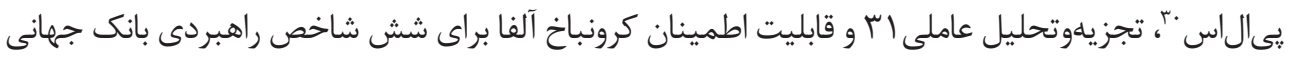

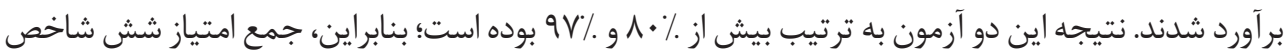

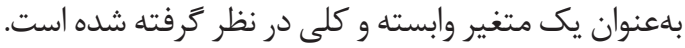

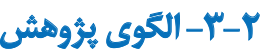

$$
\text { مدل رگرسيونى كه در اين يزوهش برآورد شده است، به شرح زير است: }
$$

INS-COMi $=\alpha 11+\lambda 11 \mathrm{PDIi}+\lambda 12 \mathrm{IDVi}+\lambda 13 \mathrm{MASi}+\lambda 14 \mathrm{UAIi}+\lambda 15 \mathrm{LTO} i+\lambda 16 \mathrm{INDi}+\varepsilon 1 i$

$$
\text { كه در آن: }
$$

فجموع امتيازات شش شاخص راهبردى بانك جهانى، PDI شاخص فاصله قدرت، IDS-COM

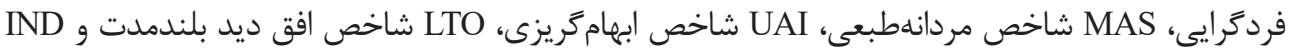

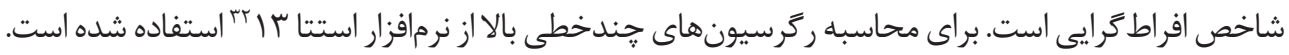

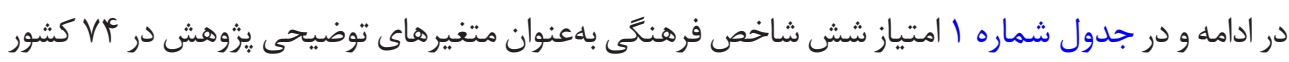

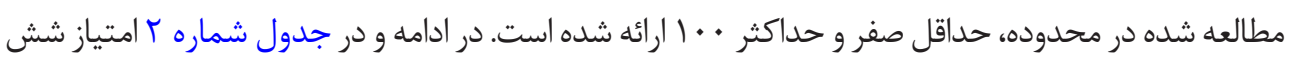

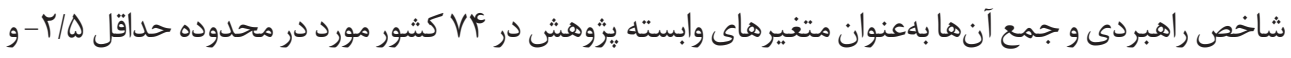

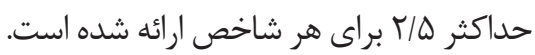

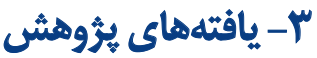

در اين بخش، يافتههاى يزوهش در دو بخش آمار توصيفى و آمار استنباطى تدوين شده است و درنهايت،

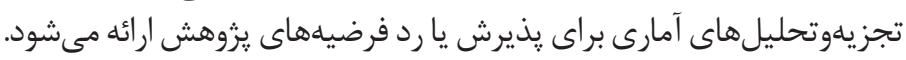

$$
\text { 五 }
$$

در كام اول، آمار توصيفى متغيرهاى يزوهش ارائه مىشود. جدول شماره ب نشاندهنده خلاصهاى از آمار

30. Smart PLS

31. Confirmatory factor analysis

32. Stata software 13 
جدول ا. امتياز متغيرهاى ثوضيحى ئروهش در FV كشور مورد مطالعه

\begin{tabular}{|c|c|c|c|c|c|c|}
\hline اقراطكرايى & افق ديد & ابجامكيزى & مرداتهلبعى & فردكرايى & فاصله قدرت & كشور \\
\hline gr & g. & v. & ma & $\Delta$ & 11 & اتريش \\
\hline prr & 18 & 9Q & fo & $r$. & v. & اردن \\
\hline$\Delta r$ & re & 99 & ץ & ש & 81 & الروكوئه \\
\hline pi & PA & N & Rr & $\Delta 1$ & $\Delta V$ & أسيانيا \\
\hline$n$ & $M$ & Q) & 81 & q. & re & الستراليا \\
\hline is & Ar & e. & $r$. & s. & $r$. & الستونى \\
\hline M & $\Delta \Delta$ & 99 & $r v$ & ra & 99 & اوكراين \\
\hline 99 & Q1 & ra & 98 & 19 & ro & انكَلستان \\
\hline sA & rq & if & gr & 91 & r. & ايالاتثتحده \\
\hline r. & \&) & vo & v. & ve & ه. & ايتاليا \\
\hline ga & $m$ & ro & 81 & v. & $r$ & ايرلند \\
\hline ov & YA & Q. & 1. & s. & r. & ايسلند \\
\hline gr & r. & N & $\Delta F$ & pq & $p q$ & أررأنتين \\
\hline 10 & \&) & v. & A. & $r$. & q. & ألبائى \\
\hline$r$. & Ar & \&Q & \&g & ev & ro & آلمان \\
\hline Ar & 10 & \&. & $r$. & $M$ & $A H^{w}$ & آنكولا \\
\hline$\Delta q$ & $\mu f$ & ve & $p q$ & r & 89 & بوزيل \\
\hline$\Delta V$ & Ar & qf & Af & Va & Eo & بلريك \\
\hline 18 & $9 q$ & AD & f. & $r$ & v. & بلغارنستان \\
\hline r. & ev & \&. & $\Delta \Delta$ & r. & A. & بنكالاش \\
\hline M & r & $\Delta \Delta$ & Q. & 10 & v. & بوركينافاسو \\
\hline$m$ & ra & 99 & M & r & er & هبرتغل \\
\hline
\end{tabular}




\begin{tabular}{|c|c|c|c|c|c|c|}
\hline الفراطِّرايي & اقث ديد & إيهامئيويزى & هرةانهطبيى & فرثكَاليي & فاصله قدرث & كشور \\
\hline if & ro & AV & et & 18 & ap & $28 \%$ \\
\hline 99 & 19 & ra & $\Delta F$ & rV & EN & يورتوريكو \\
\hline ra & $m$ & Q. & r. & ro & v. & ت ت تائزائيا \\
\hline Fa & rT & gr & $m$ & r. & ge & ت تايلند \\
\hline pq & 9 & $9 q$ & to & iv & $\mathbb{A M}$ & تايوان \\
\hline pq & is & AD & Fo & r & sq & تركيه \\
\hline A. & ir & $\Delta \Delta$ & $\Delta A$ & 18 & er & تريثيداد و توباكو \\
\hline f. & if & $\Delta ?$ & er & i) & $\Delta A$ & ايران \\
\hline rq & v. & $n^{f}$ & $\Delta V$ & $\Delta A$ & $\Delta V$ & جمهروى جك \\
\hline$\Delta f$ & ir & Pa & 80 & $r$. & 90 & جمهورى دومينيكن \\
\hline rq & $1 .$. & AS & mq & M & c. & جمهورى كره جنوبي \\
\hline 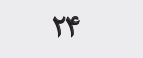 & $A V$ & r. & es & $r$. & A. & جين \\
\hline v. & एם & זי & 18 & $n$ & M & دائمارى \\
\hline r. & Ar & q. & fr & r. & q. & رمانى \\
\hline r. & A) & 98 & re & rq & 94 & روسيه \\
\hline HT & r. & Q. & f. & ro & g. & زامبى \\
\hline pr & $M$ & 95 & 90 & pe & $\Delta f$ & راين \\
\hline 19 & r. & qै & f. & 19 & $8 q$ & السالوادور \\
\hline $\mathrm{VA}$ & $\Delta r$ & rq & $\Delta$ & $n$ & r & سوند \\
\hline 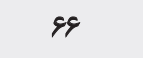 & ne & $\Delta A$ & v. & \&A & $m p$ & سوئيس \\
\hline $8 A$ & ו & A & ru & m & r & شيلى \\
\hline IV & ta & so & v. & r. & $9 \Delta$ & عراق \\
\hline ar & re & A. & c. & ro & 90 & عربستان \\
\hline$n$ & f & $\varepsilon_{\Delta}$ & f. & 10 & A. & غُنا \\
\hline
\end{tabular}




\begin{tabular}{|c|c|c|c|c|c|c|}
\hline أفراطكّرايي & افق ديد & ابهام كُيزى & مرداتفطبعي & فردكّائي & فاصله قدرت & كشور \\
\hline PA & ex & N & er & $n$ & 81 & فرائسه \\
\hline$\Delta V$ & rג & 09 & re & r & $m$ & فنلاند \\
\hline rr & TV & ff & af & M & qf & فيلييين \\
\hline $8 A$ & re & iA & Ar & A. & rq & كائادا \\
\hline 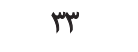 & $\Delta A$ & A. & f. & $r$ & $n$ & كرواسى \\
\hline Ar & זו & A. & gr & Ir & ov & كلمبيا \\
\hline TD & lif & ఎ. & EQ & r. & Vo & لبنان \\
\hline ir & $9 q$ & gr & 9 & v. & pif & لتونى \\
\hline$\Delta$ & ge & v. & ه. & \&. & r. & لوكزامبورى \\
\hline rq & ru & १พ & ep & 9. & $8 A$ & لهيستان \\
\hline$\pi$ & $m$ & \&A & Qr & ra & A. & ليبي \\
\hline 18 & Ar & $8 \Delta$ & 19 & s. & RT & ليتوائي \\
\hline 88 & pr & $q$ & ev & $\Delta q$ & ه. & مالتا \\
\hline$\Delta V$ & i) & re & Q. & re & $1 .$. & مالزى \\
\hline r & $\Delta$ & Ar & $M$ & 1. & is & هجارنستان \\
\hline r & $r$ & A. & Fo & ra & v. & مصر \\
\hline 9v & me & AY & eq & r. & A) & هكزيك \\
\hline TA & If & 81 & QH & pe & v. & موراكو \\
\hline A. & 11 & pr & rA & 10 & 10 & موزامبيك \\
\hline$\Delta \Delta$ & ra & Q. & 1 & eq & m & نروز \\
\hline Af & ir & $\Delta \Delta$ & 8. & $r$ & A. & ثيجريه \\
\hline VD & $m$ & $p q$ & $\mathbb{A M}$ & va & M & نيوزلند \\
\hline $1 .$. & 18 & ve & $n^{m}$ & ir & A) & ونزوئلا \\
\hline זם & $\Delta V$ & $r$. & f. & r. & V. & ويتنام \\
\hline
\end{tabular}




\begin{tabular}{|c|c|c|c|c|c|c|}
\hline أفراطَّرايي & اقق ديد & إيهامئيزي & هروانهلطبعي & فردئرايي & فاصله قدرث & كشور \\
\hline \&A & eV & هr & if & A. & ra & هلند \\
\hline re & Q) & r. & $\Delta F$ & pa & $w$ & هند \\
\hline IV & \&) & rq & $\Delta V$ & ro & EA & هنك كنى \\
\hline a. & ra & $1 .+$ & $\Delta V$ & $r \Delta$ & q. & يويونان \\
\hline
\end{tabular}

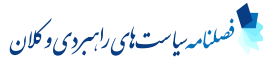

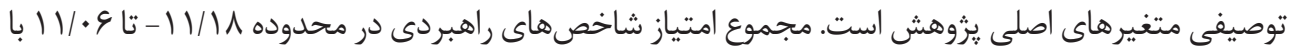

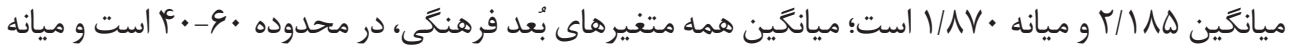

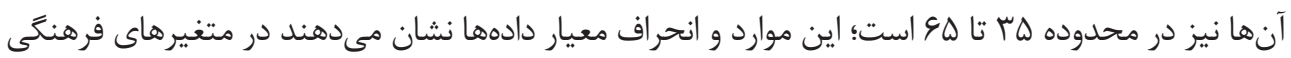
دادههاى يرت وجود ندارد.

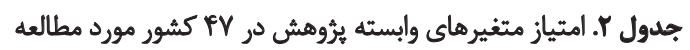

\begin{tabular}{|c|c|c|c|c|c|c|c|}
\hline جمع & كسترل & عاكميتقائون & نظيفيت & تأثير كَثلارى & ثبات سياسى & مسئوليتهيذيرى & كشور \\
\hline NHA & Vor & WNA & IRT & $V / \Delta 1$ & - Mr & $1 / 7 q$ & اتويش \\
\hline$-\cdot / \Delta r$ &.$/ M V$ &.$/ \mu$ & $.1 . \Delta$ &.$/ f F$ & $-\cdot|\Delta|^{\mu}$ & $-\cdot N G$ & 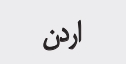 \\
\hline eprq & V/T & .184 & $-+/ 4 q$ & $\cdot / \Delta \Delta$ & $1 / 1$ & $1 / 1 A$ & الروكوئه \\
\hline$\Delta / T$ &.$/ \Delta F^{e}$ & .14 & $1 / \cdot 1$ & $V / M r$ & .119 & $1 / .8$ & الهيليا \\
\hline QTq & $\mathrm{WW}$ & INA & $1 / 9$. & $V / \mathbb{A}$ & .19 & $1 / m$ & الستراليا \\
\hline Whe & $|/ M|$ & $1 / m e$ & IN & V/r & .189 & $1 / T$. & استّونى \\
\hline$-p / p q$ & $-\bullet / A P$ & $-\cdot M$ &.$- / N T$ & -.101 & $-1 / 19$ & $.1 . r$ & اوكراين \\
\hline No & $V / M A$ & Ver & IVE & $1 / 81$ &.$/ 1 \mathrm{~s}$ & $1 / \pi F$ & أهلستن \\
\hline V/PT & 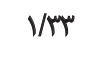 & WeV & $1 / 0$. & $1 / 19$ & $\cdot / r \Delta$ & $1 / 1$ & ايالاتمثحله \\
\hline r/qu & .1 .0 &.$/ T V$ & $\cdot M$ &.$|\Delta|$ & $\cdot / r \Delta$ & $1 / . F$ & إيتاليا \\
\hline NTH & VEM & VAP & $W^{F}$ & $1 / 7 \%$ & $\cdot / M$ & $1 / 79$ & إيرلند \\
\hline NNE & 1/99 & $1 / \Delta 1$ & I/TA & $\mid / F I$ & I/T & $1 / m F$ & إيسلند \\
\hline
\end{tabular}




\begin{tabular}{|c|c|c|c|c|c|c|c|}
\hline 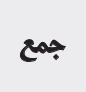 & كتبرل & حاكميتقانون & كظارثيث & تأثير كَّثارى & ثبات سياسى & هسنوليتيذيرى & كشيو \\
\hline$-+/ 19$ & $-* / \mu$ &.$- / / 4 \Delta$ & $-+/ \mathbb{V}$ & $+/ M$ &.$/ M T$ &.$/ \Delta F$ & آررأنيين \\
\hline$-+/ 1 F$ & $-* / 4$ & هם &.$/ 19$ & $\%$ & ع &.$/ 18$ & ألبانى \\
\hline $9 / \cdot 9$ & V/Ar & $1 / 81$ & VAY & $1 / M^{e}$ & . NE & $1 / \pi$ & ألمان \\
\hline-81.9 & $-1 / 4$ & $-1 / \cdot 1$ & $-1 / \cdots$ & $-1 /+5$ &.$- / 19 q$ & $-1 / 1 V$ & أَثكولا \\
\hline.$- / 19$ &.$- / p i$ & $-.1 \cdot 1$ & $-\cdot / M$ &.- .111 &.$- / \% \Delta$ &.$/ 2 \mathrm{~V}$ & برزيل \\
\hline$V / \Delta$ & $1 / 8$. & $1 / 4$. & $1 / M P$ & $1 / m$ & - MeA & I/4ه & بلزيّيى \\
\hline V/rY &.$- / 18$ & $-\cdot 1 \cdot i$ & .189 &.$/ 7 q$ & $1 . r$ &.$/ 48$ & بلغارسئن \\
\hline -r/FA & $-\cdot / \mathrm{A}$ &.$- / 109$ & $-+/ 1$ & -.189 & $-1 / T e$ & -108 & بنغلاش \\
\hline$-t / R L^{2}$ & $-\bullet / N$ &.$- / 4 a$ & $-* / 4$ & $-+/ \Delta \Delta$ & $-+/ 9 \Delta$ & .1 .4 & بوركينالفاو \\
\hline$g / M f$ & $+/ Q$ & VIr & - IAF & $1 / \pi r$ & $V \cdot r$ & I/IV & يرتغال \\
\hline$-+/ \mu \Lambda$ & $-+/ \pi \Delta$ &.$- / 79$ & $\cdot(\Delta)$ &.$- / 1 \mathrm{r}$ & $-+/ 18$ &.$/ M A$ & يرو \\
\hline T/Ke & 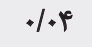 & $\cdot / 8 \lambda$ & -/9ब & $+/ r A$ & $\cdot|A|$ &.$/ 4$ & يورتوريكو \\
\hline$-r / F A$ &.$- / 01$ & $-1 / 49$ &.$- / 19$ & $-.1 \Delta \Delta$ & $-\infty \mid+1$ & $-.11 \mathrm{~A}$ & تالثرأيا \\
\hline$-1 / 91$ & $-\cdot / e$ & .1 .1 &.$/ \mathrm{V}$ &.$/ M F$ &.$- / 94$ & $-1 / 1$ & تيليلن \\
\hline g/er & 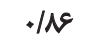 & lif & $1 / r q$ & $I / T V$ &.$/ 94$ & $1 / \cdot r$ & ت ت تيوان \\
\hline$-r / M^{e}$ & $-\cdot / 4$ &.$- / 18$ & $\cdot r$ & .1 .0 & $-r / \%$ & -.184 & تركيه \\
\hline$\cdot M$ &.$- / 48$ & -.118 & .1 .9 & . $M r$ & - / M & .18 & ترينيانوتوباكو \\
\hline$-p / 9 q$ & $-\cdot M r$ & $-\cdot M$ & $-1 / \pi r$ & $-\pi / r$ & $\rightarrow / M^{e}$ & $-1 / 49$ & ايران \\
\hline$\Delta / 8 q$ & $. / D \mid$ & $y+9$ &.$/ 99$ & $1 / .8$ &.$/ 99$ & $1 / \cdot 0$ & جمهورى جك \\
\hline$-+/ 91$ & $\rightarrow / N A$ & $-+/ 179$ & $-+1+V$ & $-\pi / T \Delta$ & Arq &.$/ 19$ & جمهورى تومينيكن \\
\hline$r / f q$ &,$+ H$ & V/IF & $1 / 1$ & $y+Y$ &.$/ 18$ & $.19+$ & جمهورى كره جنوبى \\
\hline$-r / \Delta)$ & $-* / T \Delta$ &.$- / T r$ & $-+/ 48$ & ./WE & $-+/ \Delta T$ & $-1 / 94$ & جين \\
\hline
\end{tabular}




\begin{tabular}{|c|c|c|c|c|c|c|c|}
\hline جمع & فتساد & حاكميتثانون & كظارث & تأثير كَّارى & ثبات سياسى & مسئوليثنانيرى & كشور \\
\hline $9 / 9$ & T/MF & $1 / 9$. & $1 / \Delta A$ & $V / A C$ & $\cdot / \Lambda \Delta$ & $1 / F V$ & داثمارك \\
\hline $1 / 0$ & $\%$ &.$/ \mu$ & .109 & $-+/ 1 V$ &.$/ T r$ &.$|\Delta|$ & 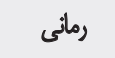 \\
\hline$-r / r^{m}$ & -.118 & $=. N$ & 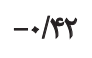 &.$- / M$ & $-1 / 19$ & $-|/ M|$ & روسيه \\
\hline$-1 / 28$ & $-* / f$ & $-\cdot / r$ & $-* / 1 A$ & -.188 & .111 & $-\cdot / r$ & زالمبيى \\
\hline NIS & $\mid(\Delta)$ & Wra & I/PT & V/Ar & $1 / \cdot 1$ & $1 / .$. & أين \\
\hline$-1 / T \Delta$ & $-\bullet / \Delta V$ & $-\bullet / M$ & $.1+9$ & $-\cdot / r A$ & -1.8 &.$/ T A$ & السالوادور \\
\hline $1 . / r \alpha$ & T/M & $r / P$ & //1A & $1 / 19$ &.$/ 4$ & $1 / 0$ & سوئد سون \\
\hline $1 \cdot M$ & $M / \theta$ & V/ar & $1 / 91$ & $r / \cdot r$ & I/TH & 1/48 & سوئيس \\
\hline slif & $M$ & W/r & $\mathbb{V} / \mathrm{r}$ & $V / * r$ & .101 & $1 / *$. & شيلى \\
\hline$-N V \Lambda$ & $-1 / 4$ & $-1 / V$ & $-1 / / r$ & $-I / T E$ & -r/TA & $-1 / \cdot 1$ & عراق \\
\hline$-1 / \pi 8$ & d & drV & $.1 \% 1$ & drf & $-\infty / \Delta$ & $-1 / 21$ & عربستلن \\
\hline.$- / 14$ & $-+/ 1 V$ & $\%$ & $--/ \pi r$ & $-+/ r$ & $-+/ 18$ & .194 & غنا \\
\hline spe & $1 / M$ & $\mid(n)$ & $V / V$ & $\mid / F i$ & .1 .8 & $1 / \cdot A$ & فرالنسه \\
\hline $1 . / N T$ & T/MA & $T / \cdot Y$ & V/AT & $1 / 1 \Delta$ & .19 & $1 / 1 e q$ & فiا \\
\hline$-T / 1$ & $-\cdot / \Delta r$ &.$- / p$ & .1. &.$- .1 \cdot 1$ & $-1 / r^{n}$ &.$/ 1 f$ & فيلييين \\
\hline v/u & $1 / 4$ & V/AF & $1 / M^{e}$ & $V / 1$. & $1 / M F$ & $1 / \pi A$ & كاناما \\
\hline T/GA & .119 &.$/ N 4$ & . &.$/ 89$ & .181 & . / $\Delta r$ & كرواسى \\
\hline$-1 / 11$ & $-* / m \varphi$ &.$- / \pi$ &.$/ 4$ & $.1 \cdot Y$ &.$- / 48$ & +11 & كلمبيا \\
\hline$-r / v \wedge$ & $-+/ 97$ &.$- / N$ & $-* / \mu$ & $-\cdot / \Delta r$ & $-V / \Delta F$ & $-\cdot / \Delta T$ & لبنلن \\
\hline$r / v \wedge$ &.$/ 199$ & .190 & $1 /+1$ & $V * *$ &.$/ 199$ & $+/ A V$ & لتونى \\
\hline 1.1 .0 & $r / \cdot \lambda$ & $m$ & 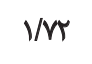 & $1 / 89$ & $\mid / 4$ & $1 / 45$ & لوكزامبورك \\
\hline t/Ft & - IVD & .181 & $.19 \Delta$ & .189 &.$/ 101$ & -/AF & لهستل \\
\hline
\end{tabular}




\begin{tabular}{|c|c|c|c|c|c|c|c|}
\hline جمع & فتشرل & حاكميتقانون & نظارث & تأثيركثنارى & ثبات سياسى & هسئوليثيذيرى & كشير \\
\hline$-11 / M$ & $-V / \Delta V$ & $-I / A Y$ & $-T / T Y$ & $-1 / 19$ & $-r / T I$ & $-1 / T V$ & لييى \\
\hline$\Delta / N$ & $.18 \mathrm{~V}$ & $V / r$ & V/F & $1 / \cdot 9$ &.$/ 1$ &.$/ 99$ & ليتوائى \\
\hline $8 / 19$ &.$M T$ & $1 / \cdot A$ & $1 / 18$ &.$/ 90$ & $V \cdot A$ & IT. & هالثا \\
\hline IVA &.$/ 11$ & - /ar & $\cdot M$ & $\cdot / M$ & 11 &.$- / 4 r$ & مالزي \\
\hline$n$ &.$/ * 1$ &.$|\Delta|$ & .18. &.$/ 1 \%$ & $\cdot(n)$ &.$/ \pi V$ & هجارستان \\
\hline$-ه / T V$ &.$- / g r$ &.$- / 4 i$ &.$- / 9 Y$ & -.188 & $-I / R T$ & $-1 / M$ & هصر \\
\hline$-1 / N$ &.$- / W$ &.$- / 0$ &.$/ r q$ &.$/ 1 F$ & $-\bullet / W$ & -.1 .9 & مكزيك \\
\hline$-1 / \Delta$ &.$- / 10$ &.$- / 14$ & $-* / \pi r$ & -.11 &.$- / 7 q$ & -.180 & موراكو \\
\hline$-F / M$ & $-\cdot / A V$ & $-1 / \cdot r$ & $-* / V$ & -.1110 & $-1 / * 0$ & $-+/ 4 q$ & موزامبيك \\
\hline 1.100 & $r / T$. & $r /+r$ & W & $V / M$ & WIV & $1 / D A$ & نزوز \\
\hline$-E / T \Delta$ & $-1 /+f$ & $-1 / \cdot \Delta$ & $-+/ 9 r$ & $-1 / \cdot 9$ & $-1 / 1 \Delta$ & $-\cdot / \mu$ & نيجريه \\
\hline $11 / \cdot 8$ & $r / \mu$. & VI/ & $r / * F$ & $1 / N$ & $1 / 79$ & $1 / F F$ & نيوزألد \\
\hline$-q / \cdot r$ & $-1 / 149$ & $-T / M$ & $-F / \cdot 0$ & $-1 / 4 q$ & $-1 / \cdot r$ & $-1 / 1 \%$ & وتوزوتلا \\
\hline$-Y / \cdot Y^{w}$ & $-\cdot / f^{e}$ & .1 .0 & $-\bullet / P a$ & .1 .1 &.$/ 1 \mathrm{~V}$ & $-|/|+1$ & ويتنم \\
\hline $1 \cdot 1 \cdot r$ & $1 / 90$ & $1 / 19$ & $1 / 4$ & V/Af & .119 & I/RA & هلثد \\
\hline$-1 / 1 r$ & $-* / \pi$ &.$- / \cdot v$ & $-*|r|$ & .1 &.$- / 9 \Delta$ &.$|p|$ & هند \\
\hline Ne & $V / D A$ & IV. & $r / 1 Q$ & $1 / N$ & - MAP &.$M$ & هنك كنى \\
\hline$V \cdot r$ & $-.1+\infty$ &.$\pi$ &.$/ 10$ &.$/ M I$ &.$- / 16$ & .180 & يوئن \\
\hline
\end{tabular}

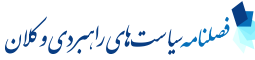

r-1-1 - جمع شاخصهاى راهبردى

بر اساس جدول شماره أ، امتياز جمهورى اسلامى ايران در اين شاخص، كمتر از ميانخين است. كشورهاى

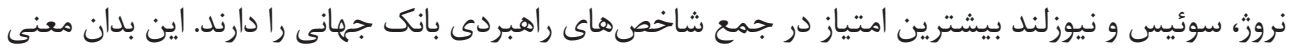

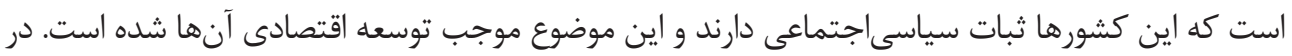


جدول ץ. آمار توصيفى متغيرهاى يُوهش

\begin{tabular}{|c|c|c|c|c|c|}
\hline حداكثر & حداقل & انحراف معيار & هيانه & ميانكين & هتغيرها \\
\hline 111.8 & $-11 / 11$ & $\Delta / g_{T A}$ & V/AV & $T / M$ & جمع شاخصهاى راهبردى \\
\hline $1 .$. & 11 & $r \cdot / 8 \cdot Y$ & 80 & 811.91 & فاصله قدرت \\
\hline 91 & ir & rr/ger & $r$ & $92 / .90$ & فردمرايع \\
\hline 90 & $\Delta$ & WEA & Q. & PNAPI & مرداثائهطبعى \\
\hline 1.. & m & $r+10 \cdot 4$ & sa & 981.14 & إيهامريزى \\
\hline $1 .$. & f & $r \varphi / . r q$ & r & PY/GTY & افق ديد بلندمدت \\
\hline 1.. & $r$ & $r H / \Delta F Y$ & $p q$ & PNEVE & افراطكرايى \\
\hline =ئك رابمر & il & & & & هاى ثرؤوهشك \\
\hline
\end{tabular}

جدول F. آمار توصيفى شاخصهايى يُوهش براساس كشورها

\begin{tabular}{|c|c|c|c|c|c|c|c|}
\hline \multirow{2}{*}{\multicolumn{3}{|c|}{ 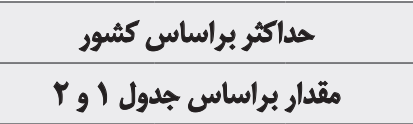 }} & \multirow{2}{*}{\multicolumn{3}{|c|}{ مقدار براساس جدول براساس كشور }} & \multirow{4}{*}{ ايران } & \multirow{4}{*}{ جمع شاخص هاهيرى } \\
\hline & & & & & & & \\
\hline \multirow{2}{*}{ نيوزلند } & سوئيس & نروز & لييى & ونزووثلا & عراق & & \\
\hline & $1 . / n$ & $1.1 \Delta \Delta$ & $-11 / 11$ & $-q \cdot r$ & $-N Y A$ & & \\
\hline مالزى & اوكراين & عربستان & نيوزلند & دانمارك & اتتريش & \multirow{2}{*}{$\Delta A$} & \multirow{2}{*}{ فاصله قدرت } \\
\hline $1 .$. & 99 & 98 & rr & M & 11 & & \\
\hline \multirow{2}{*}{$\begin{array}{l}\text { آمريكا } \\
91\end{array}$} & استراليا & أتكليس & بوركينافاسو & كلمبيا & وئزوتلا & \multirow{2}{*}{ Pi } & \multirow{2}{*}{ فردكرايى } \\
\hline & 9. & 19 & 10 & $r$ & $\pi$ & & \\
\hline \multirow{2}{*}{ خه } & هجارستان & آلبانى & لتونى & نروز & سوئد & \multirow{2}{*}{ rr } & \multirow{2}{*}{ مردانهطبعى } \\
\hline & $M$ & A. & 9 & $\wedge$ & $\Delta$ & & \\
\hline \multirow{2}{*}{$\begin{array}{l}\text { ي يونان } \\
1 . .\end{array}$} & اروكوثه & بيرتغال & هنك كنى & سوثد & داثمارك & \multirow{2}{*}{$\Delta q$} & \multirow{2}{*}{ إيهامكريزى } \\
\hline & 99 & 99 & Tq & pq & rr & & \\
\hline \multirow{2}{*}{ كره جنوبى } & تايوان & راين & هوزامبيك & مصر & غنا & \multirow{2}{*}{ if } & \multirow{2}{*}{ افق ديد بلندملت } \\
\hline & q & $M$ & 11 & $v$ & $r$ & & \\
\hline \multirow{2}{*}{$\begin{array}{l}\text { وئزوثلا } \\
1 . .\end{array}$} & يورتوريكو & هزيك & ألبائى & لتونى & هصر & \multirow{2}{*}{ f. } & \multirow{2}{*}{ اقراطكرايى } \\
\hline & 99 & จท & 10 & ir & $f$ & & \\
\hline
\end{tabular}


طرف مقابل كشورهاى ليبى، ونزوئلا و عراق كمترين امتياز را در اين شاخص داشتند.. r-I-Y- فاصله قدرت

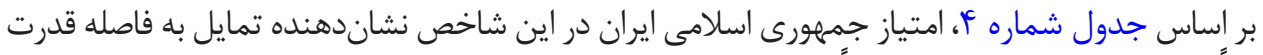

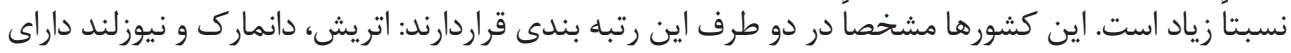

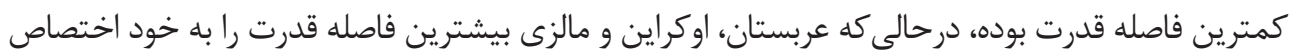

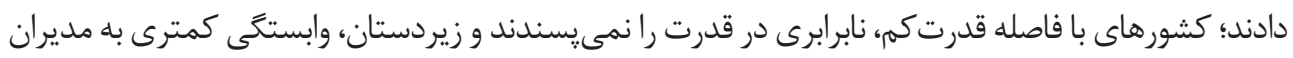

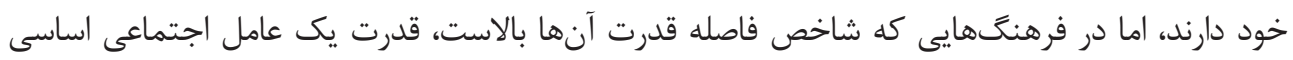

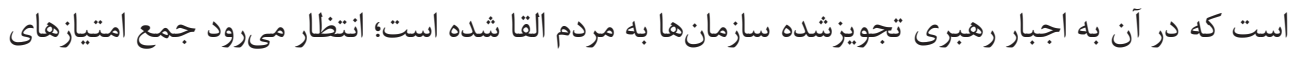

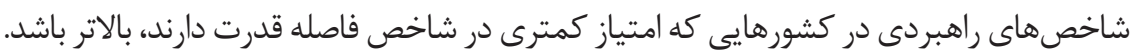

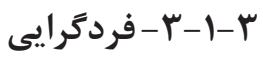

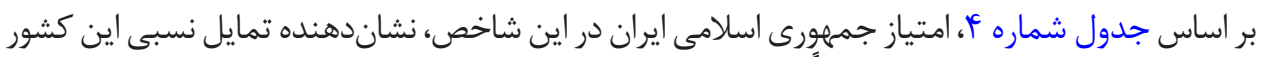

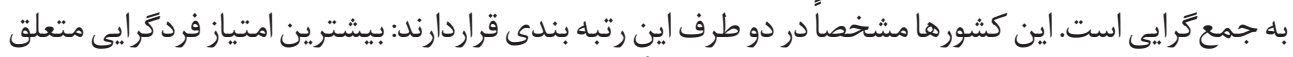

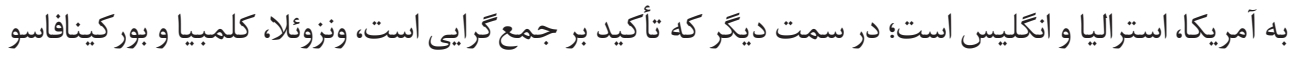

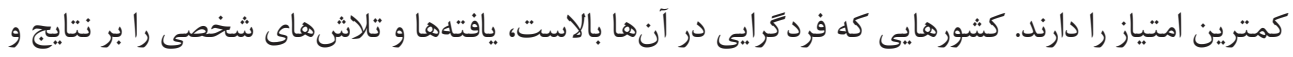

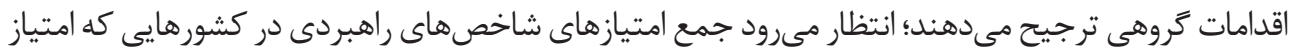
فردَرايى آنها بيشتر است، بالاتر باشد.

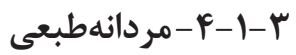

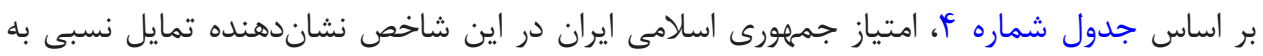

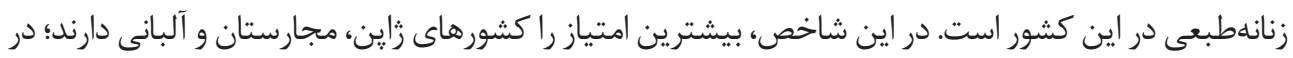

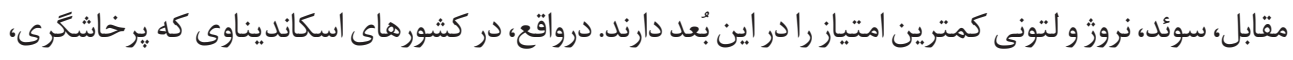

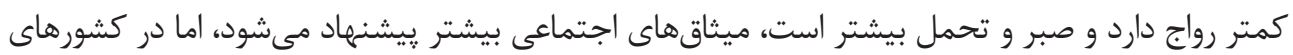

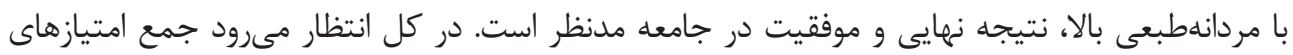

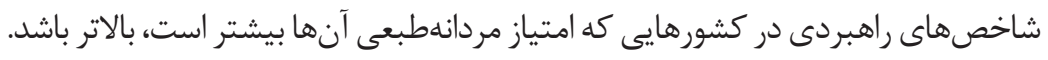

\section{r-1-ه - ابهامتريزى}

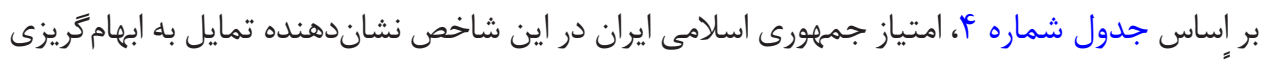

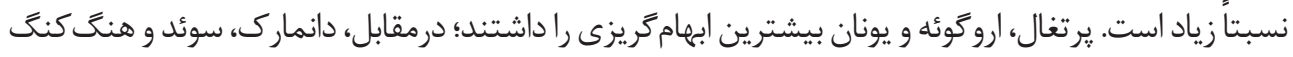

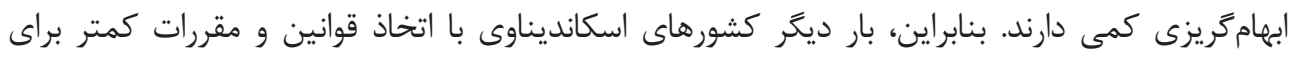

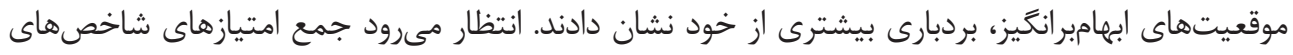


راهبردى در كشورهايى كه ابهامكريزى آنها بيشتر است، بالاتر باشد.

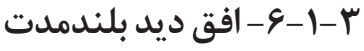

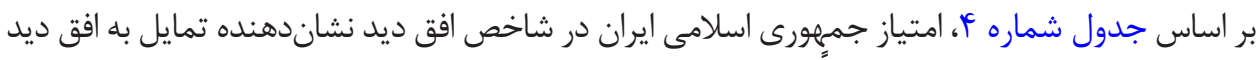

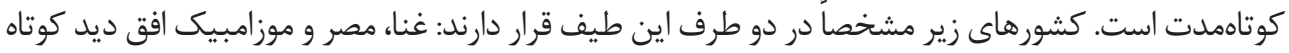

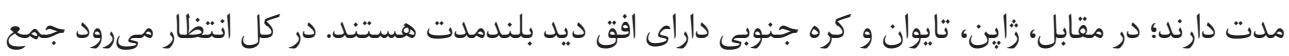

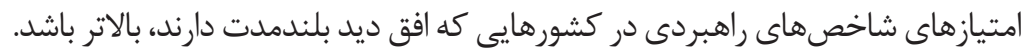

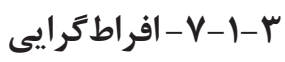

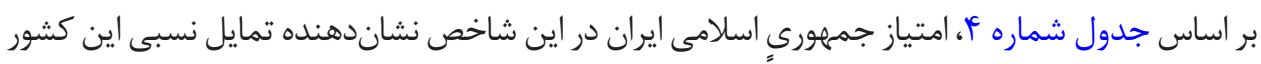

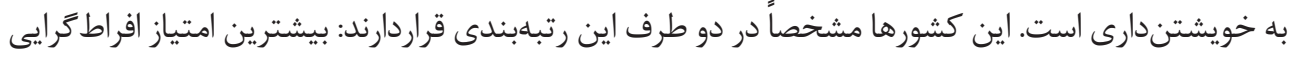

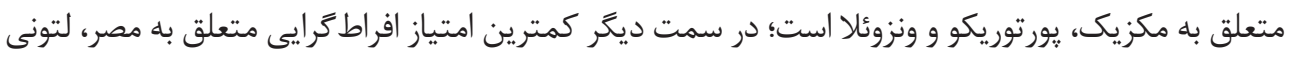

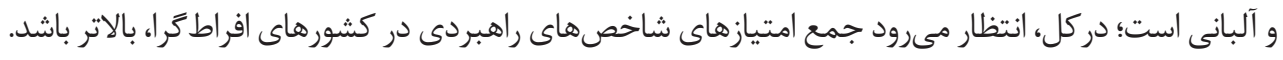

\section{r-r}

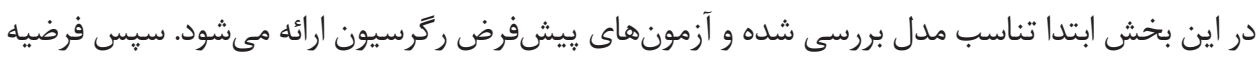

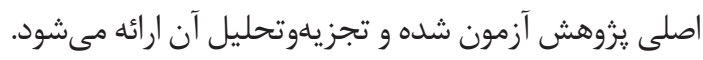

\section{ץ-ץ-1- تناسب مدل}

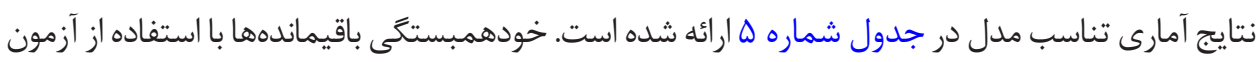

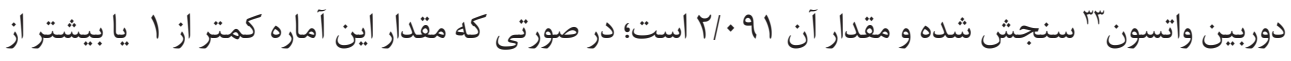

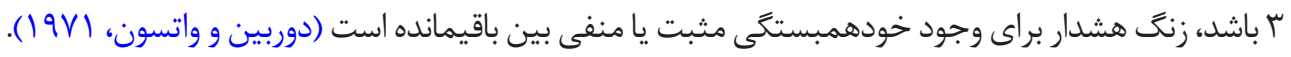

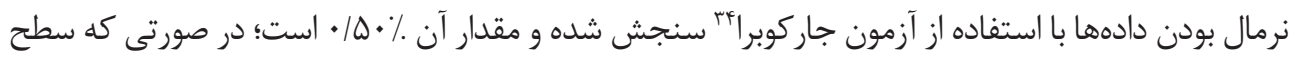

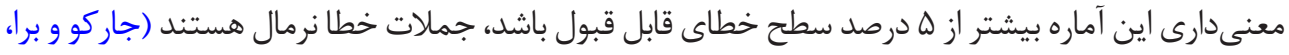

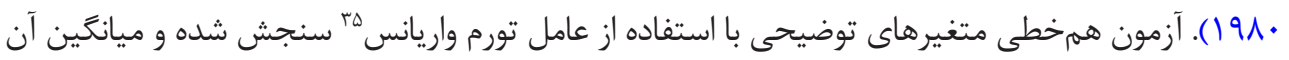

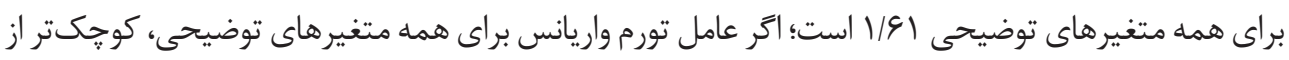

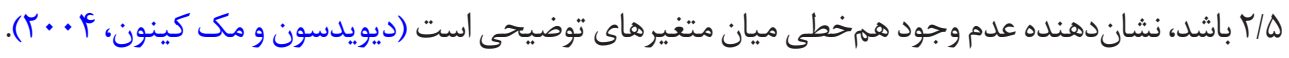

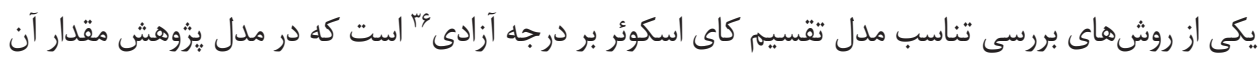

33. Durbin-Watson

34. Jarque-Bera

35. Variance Inflation Factor (VIF)

36. Degree of Freedom 
جدول ه. تناسب مدل يثروهش

\begin{tabular}{|c|c|c|c|c|}
\hline \multicolumn{2}{|c|}{ آزمون عامل ثورم واريانس } & \multicolumn{3}{|c|}{ خلاصه كلى از ثناسب مدل } \\
\hline مقدار & متغير & ميزان مطلوب & نتايج & أزمونهاى أمارى \\
\hline trea & فاصله قدرت & بين او r & $5 / .91$ & آزمون دوربين واتتسون \\
\hline T/M & فردمرايي & بيشتر از ه درصد & $.10+$ & آزمون جاركوبرا \\
\hline $1 / \cdot 0$ & مردانهطبعى & كمتر از r & $1 / 199$ & كاى اسكوار \\
\hline Whr & إيهامكريزى & كمتر از هدرهد & 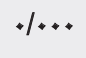 & Fتمال آماره F \\
\hline$|x|$ & افق ديل بلندملت & 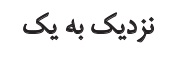 & $\cdot N \cdot \Delta$ & ضريب تعيين تعديل شله \\
\hline D/F & افراطكرايى & كمتر از ه/ه & $1 / 81$ & ميانكين عامل تورم واريانس \\
\hline
\end{tabular}

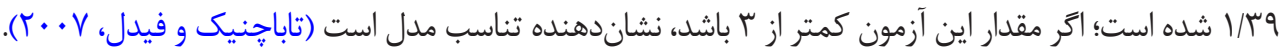

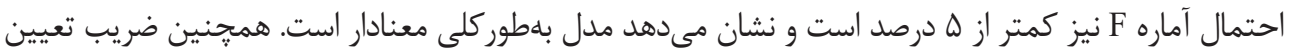

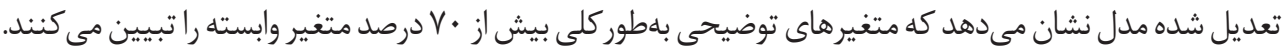

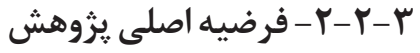

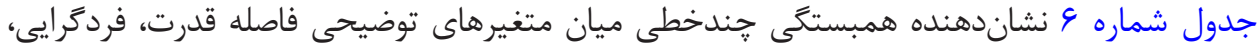

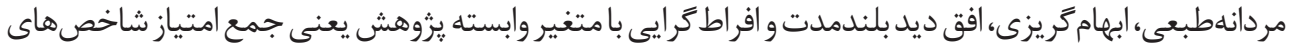

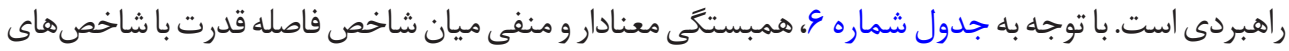

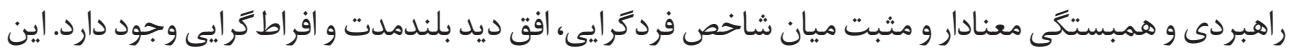

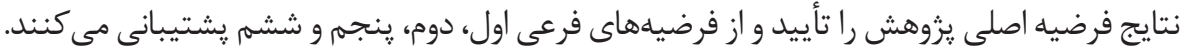

$$
\text { r-r-r-r - r- آزمونهاى اضافى }
$$

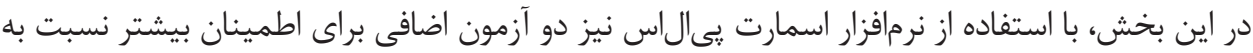

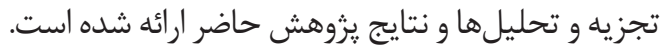

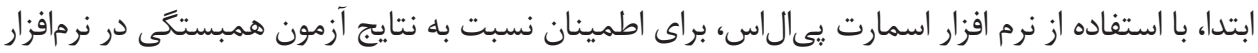

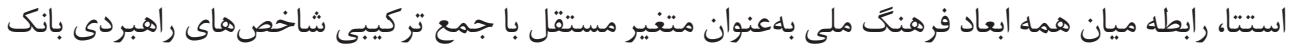

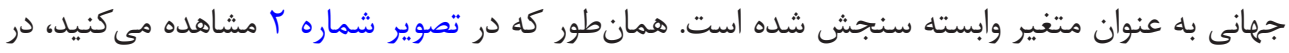

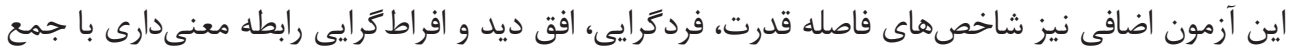


جدول \&. رابطه ميان ابعاد فرهنك ملى با جمع شاخصهاى راهبردى

\begin{tabular}{|c|c|c|c|c|}
\hline \multicolumn{4}{|c|}{ متغير وابسته: جمع امتياز شاخصهاى راهبردى } & \multirow{2}{*}{ متغير هاى توضيحى } \\
\hline نتيجه آزمون & نوع ارثباط & التمال متغير توضيحى & ضريب مثغير توضيحى & \\
\hline يُذيرش فرضيه & منفى & $\%$ &.$- / N r \Delta r$ & فاصله قدرت \\
\hline يذيرش فرضيه & همبت & $+1+11$ & $\% \Delta V^{e}$ & فردمرايى \\
\hline ر إدرضيه & 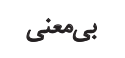 & $\cdot M T$ & $-.1 \cdot \mathrm{Mpr}$ & مردانهطبعى \\
\hline رد إنرضيه & 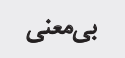 &.$/ 9 m$ & $.1 .+10$ & إيهامكريزى \\
\hline يذيرش فرضيه & مثبت & $\%$ & $.1 \cdot A N \cdot$ & أقت ديل بلندملت \\
\hline يذيرش فرضيه & مثبت &.$|+r|$ & 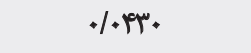 & افراطكرايى \\
\hline
\end{tabular}

شاخصهاى راهبردى بانكى جهانى دارند كه بر يذيرش فرضيه اول، دوم، ينجم و ششم يزوهش تأكيد مى كند.

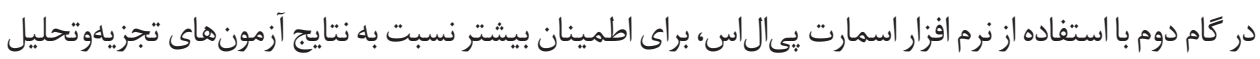

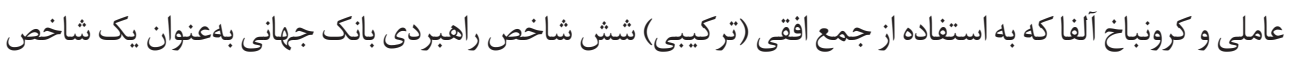

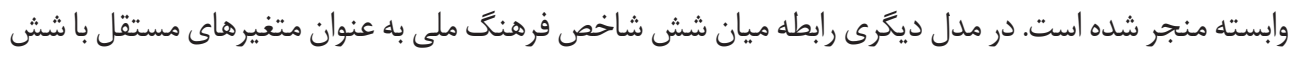

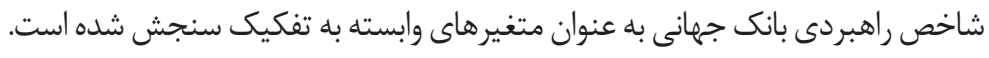

همانطور كه در تصوير شماره ب مشاهده مى كنيد، در اين آزمون اضافى نيز شاخصهاى فاصله قدرت،

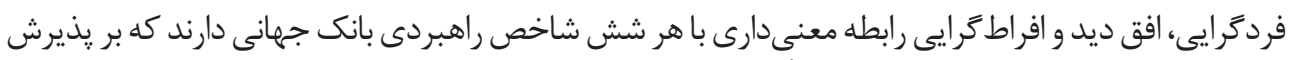

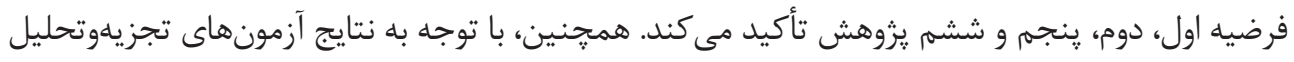

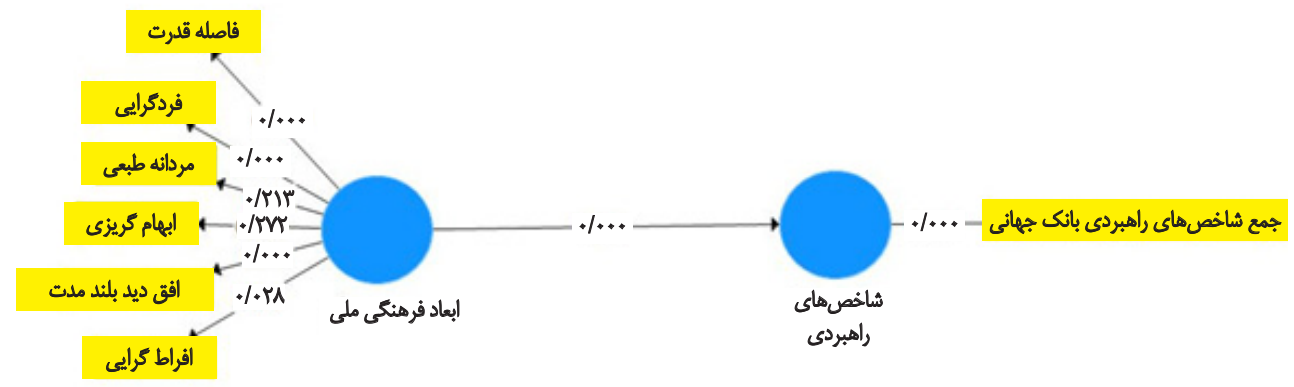

20

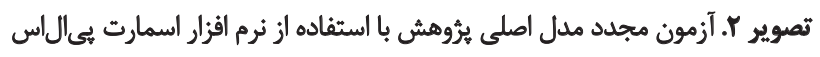



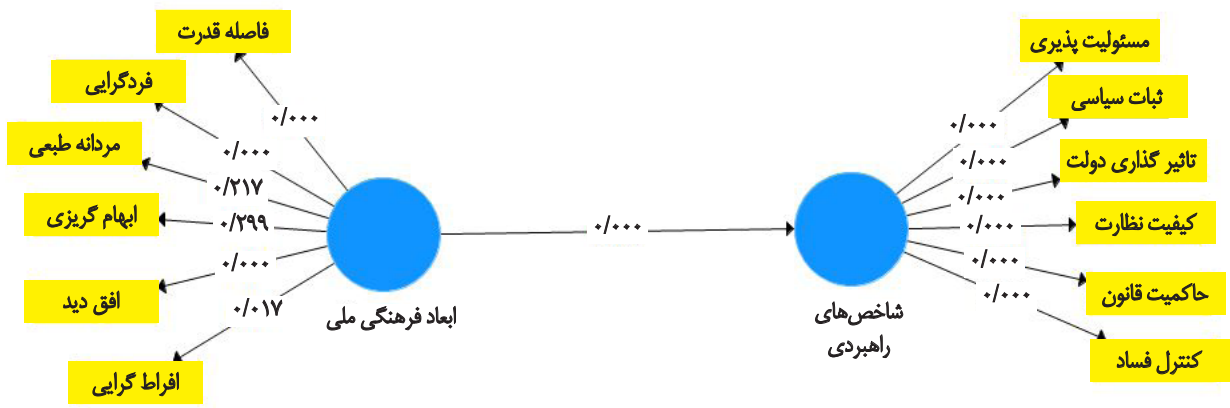

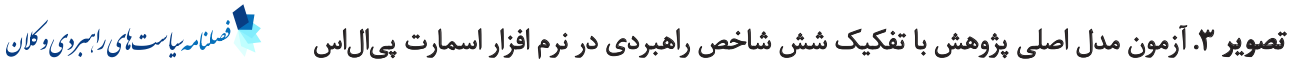
عاملى و كرونباخ آلفا و اينكه همه شاخصهاى راهبردى معنى دار شده است. بنابراين، استفاده از جمع افقى (تركيبى) براى شاخص هاى راهبردى بانك جروانى قابل توجيه است استه

\section{ع- بحث ونتيجليَيرى}

رابطه ميان فرهنَ ملى با تغييرات شاخصهاى راهبردى از اين ايده يشتيبانى ميى كند كه هنجارهاى

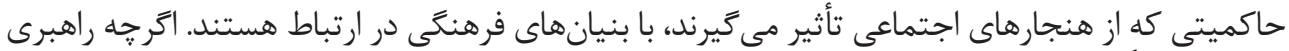

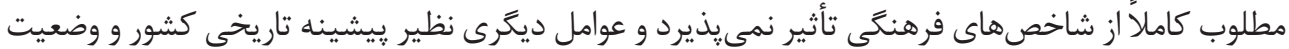

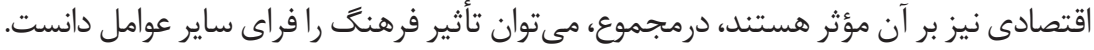

نتايج حاصل از آزمون فرضيه اصلى يزوهش نشاندهنده وجود رابطه خطى معنادار ميان شاخص هاى فرهنگى

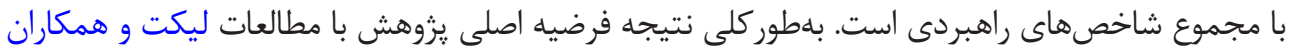

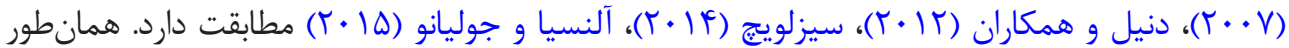

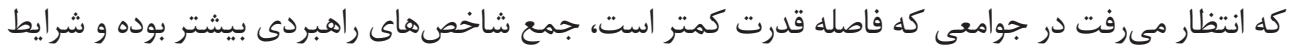

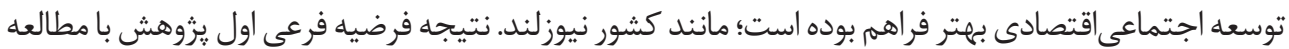

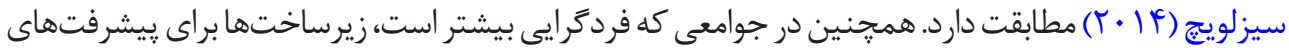

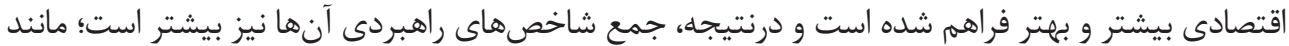

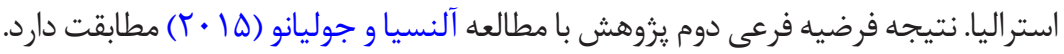

در جوامعى كه افق ديد بلندمدت بيشتر است نيز جمع شاخصهاى راهبردى بالاتر است و اين كشورها براى

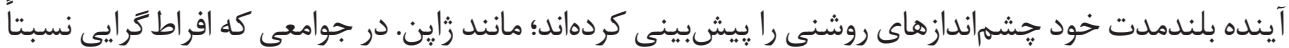

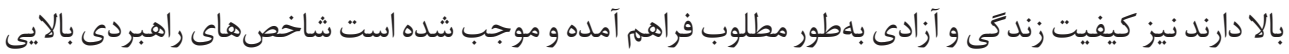

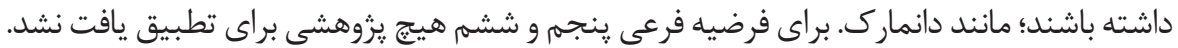




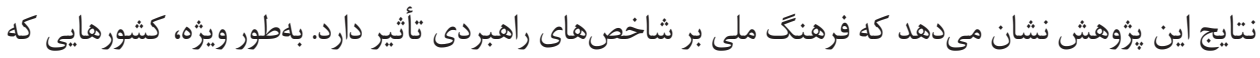

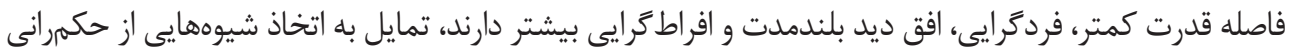

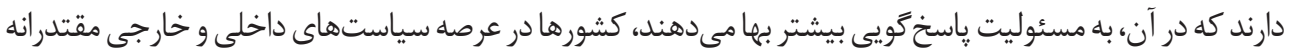

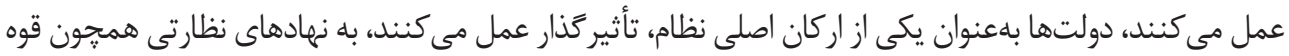

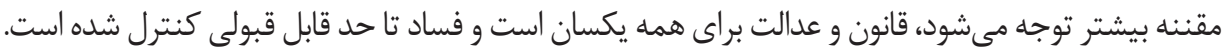

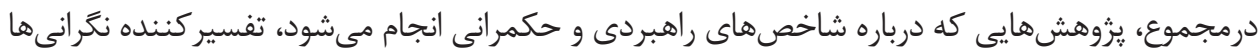

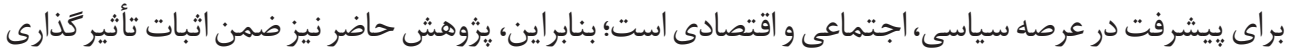

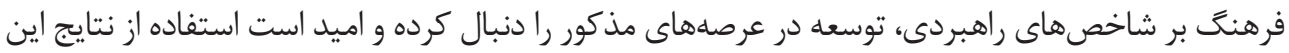

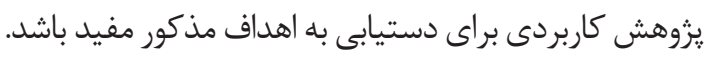

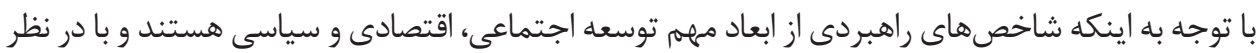

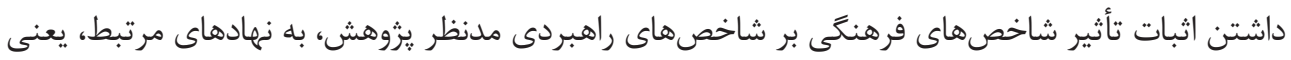

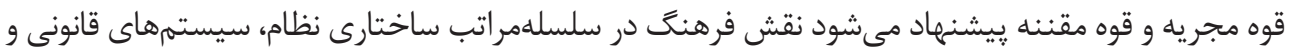

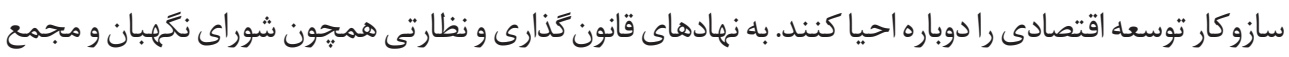

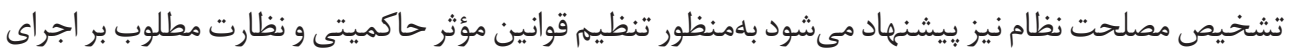

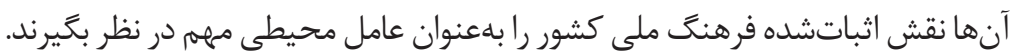

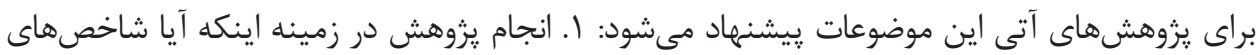

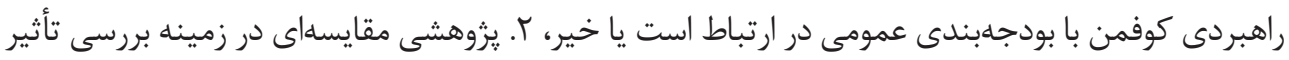

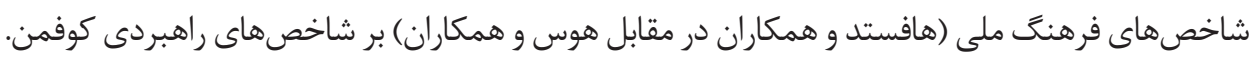

مالاحظات اخلاقي

$$
\text { مامى مالى }
$$

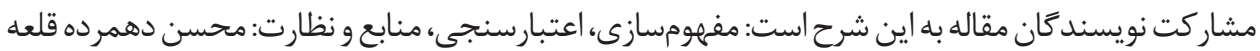

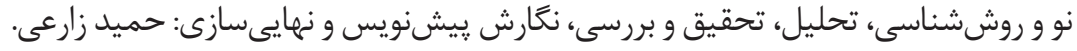

\section{تعارض منافع}

بنا به اظهار نويسند كان، در اين مقاله هيجَّونه تعارض منافعى وجود ندارد. 


\section{References}

Ahmadian, E., \& Eslami, R. (2014). [Exploring attitudes toward relationship between government and nation in Iran: A Q-methodology study (Persian)]. Quarterly Journal of Macro and Strategic Policies, 1(4), 107-133.

Alesina, A., \& Giuliano, P. (2015). [Culture and institutions (Persian)]. Journal of Economic Literature, 53(4), 898-944. [DOI:10.1257/jel.53.4.898]

Amable, B. (2003). [The diversity of modern capitalism (Persian)]. Oxford: Oxford University Press. [DOI:10.1093/01992611 $3 \mathrm{X} .001 .0001]$

Aoki, M. (2001). Toward a comparative institutional analysis. Cambridge, Massachusetts: MIT Press.

Boyd, R., \& Richerson, P. J. (1982). Cultural transmission and the evolution of cooperative behavior. Human Ecology, 10(3), 325-51. [DOI:10.1007/BF01531189]

Cieslewicz, J. K. (2014). Relationships between national economic culture, institutions, and accounting: Implications for IFRS. Critical Perspectives on Accounting, 25(6), 511-28. [DOI:10.1016/j.cpa.2013.03.006]

Daniel, S. J., Cieslewicz, J. K., \& Pourjalali, H. (2012). The impact of national economic culture and country-level institutional environment on corporate governance practices. Management International Review, 52(3), 365-94. [DOI:10.1007/s11575011-0108-x]

Davidson, R., \& MacKinnon, J. G. (2004). Econometric theory and methods. New York: Oxford University Press.

Durbin, J., \& Watson, G. S. (1971). Testing for serial correlation in least squares regression. III. Biometrika, 58(1), 1-19. [DOI:10.1093/biomet/58.1.1]

Gorodnichenko, Y., \& Roland, G. (2015). Culture, institutions and democratization. Cambridge: National Bureau of Economic Research. [DOI:10.3386/w21117]

Gorodnichenko, Y., \& Roland, G. (2017). Culture, institutions, and the wealth of nations. Review of Economics and Statistics, 99(3), 402-416. [DOI:10.1162/REST_a_00599]

Gray, S. J. (1988). Towards a theory of cultural influence on the development of accounting systems internationally. Abacus, 24(1), 1-15. [DOI:10.1111/j.1467-6281.1988.tb00200.x]

Greif, A. (1994). Cultural beliefs and the organization of society: A historical and theoretical reflection on collectivist and individualist societies. Journal of political economy, 102(5), 912-50. [DOI:10.1086/261959]

Guillén, M. F. (2001). The limits of convergence: Globalization and organizational change in Argentina, South Korea, and Spain. Princeton, New Jersey: Princeton University Press.

Hafeznia, M. R. (2008). [An introduction to the research method in humanities (Persian)]. Tehran: SAMT.

Heine, S. J. (2008). Cultural psychology. New York: W. W. Norton and Company.

Hofstede, G., Hofsted, G. J., \& Minkov M. (2010). Cultures and organizations: Software of the mind: Intercultural cooperation and its importance for survival. New York: McGraw Hill.

Hofstede, G. (1983). National cultures in four dimensions: A research-based theory of cultural differences among nations. International Studies of Management \& Organization, 13(1-2), 46-74. [DOI:10.1080/00208825.1983.11656358]

Hofstede, G. (1984). Culture's consequences: International differences in work-related values. Thousand Oaks, California: Sage. 
Hofstede, G. (2003). Culture's consequences: Comparing values, behaviors, institutions and organizations across nations. Thousand Oaks, California: Sage.

Hofstede, G. (2011). Dimensionalizing cultures: The Hofstede model in context. Online Readings in Psychology and Culture, 2(1), 8-21. [DOI:10.9707/2307-0919.1014]

Hofstede, G., \& Bond, M. H. (1988). The Confucius connection: From cultural roots to economic growth. Organizational Dynamics, 16(4), 5-21. [DOI:10.1016/0090-2616(88)90009-5]

House, R. J., Hanges, P. J., Javidan, M., Dorfman, P. W., \& Gupta, V. (2004). Culture, leadership, and organizations: The GLOBE study of 62 societies. Thousand Oaks, California: Sage.

Jarque, C. M., \& Bera, A. K. (1980). Efficient tests for normality, homoscedasticity and serial independence of regression residuals. Economics letters, 6(3), 255-9. [DOI:10.1016/0165-1765(80)90024-5]

Kaufmann, D. (2007). Governance matters VI: Aggregate and individual governance indicators, 1996-2006. Washington: World Bank.

Kaufmann, D. K., Kraay, A., \& Mastruzzi, M. (2010). The worldwide governance indicators: A summary of methodology, data and analytical issues. Washington: World Bank.

Licht, A. N., Goldschmidt, C., \& Schwartz, S. H. (2007). Culture rules: The foundations of the rule of law and other norms of governance. Journal of Comparative Economics, 35(4), 659-88. [DOI:10.1016/j.jce.2007.09.001]

Markus, H. R., \& Kitayama, S. (1991). Culture and the self: Implications for cognition, emotion, and motivation. Psychological Review, 98(2), 224-53. [DOI:10.1037/0033-295X.98.2.224]

Maurice, M., \& Sorge, A. (2000). Embedding Organizations: Societal analysis of actors, organizations and socio-economic context. Amsterdam: John Benjamins Publishing. [DOI:10.1075/aios.4]

Nisbett, R. (2004). The geography of thought: How Asians and Westerners think... differently and why. New York: Detroit Free Press.

North, D. (1990). Institutions, institutional changes and economic performance. Cambridge: Cambridge University Press. [DOI:10.1017/CBO9780511808678]

North, D. C. (1991). Institutions. Journal of economic perspectives, 5(1), 97-112. [DOI:10.1257/jep.5.1.97]

Perera, H., Cummings, L., \& Chua, F. (2012). Cultural relativity of accounting professionalism: Evidence from New Zealand and Samoa. Advances in Accounting, 28(1), 138-146. [DOI:10.1016/j.adiac.2012.03.006]

Peterson, M. F., \& Wood, R. E. (2008). Cognitive structures and processes in cross-cultural management. In D. C. Thomas \& M. F. Peterson (Eds.), Handbook of Cross-Cultural Management Research (pp. 15-33). Thousand Oaks, California: Sage. [DOI:10.4135/9781412982764.n2]

Pifeh, A., Zarei H., Jaafari Jam, H. (2017). [Do Hofstede's national culture impact on public sector budgeting practices? (Persian)]. Journal Mnagement System, 3(1):21-36.

Schmitt, D. P., Allik, J., McCrae, R. R., \& Benet Martínez, V. (2007). The geographic distribution of big Five personality traits: Patterns and profiles of human self-description across 56 nations. Journal of Cross-Cultural psychology, 38(2), $173-212$. [DOI:10.1177/0022022106297299]

Stulz, R. M., \& Williamson, R. (2003). Culture, openness, and finance. Journal of Financial Economics, 70(3), $313-49$. [DOI:10.1016/S0304-405X(03)00173-9] 
Tabachnick, B. G., \& Fidell, L. S. (2007). Using multivariate statistics. London: Pearson Education. [PMCID]

Tabellini, G. (2010). Culture and institutions: Economic development in the regions of Europe. Journal of the European Economic Association, 8(4), 677-716. [DOI:10.1111/j.1542-4774.2010.tb00537.x]

Tubadji, A. (2013). Culture-based development-culture and institutions: Economic development in the regions of Europe. International Journal of Society Systems Science, 5(4), 355-91. [DOI:10.1504/IJSSS.2013.058466]

Whitley, R. (1992). European business systems: Firms and markets in their national contexts. Thousand Oaks, California: Sage. [PMCID]

Williamson, O. E. (1993). Calculativeness, trust, and economic organization. The Journal of Law and Economics, 36(1), 453-86. [DOI:10.1086/467284] 